\title{
Investigation on the Non-Uniform Temperature Distribution of Large-Diameter Concrete Silos under Solar Radiation
}

\author{
Liang Zhao $\mathbb{D}^{\mathbb{1}}{ }^{1}$ Zhiyong Yang $\mathbb{D}^{1}{ }^{1}$ and Lijie Wang $\mathbb{D}^{2}$ \\ ${ }^{1}$ School of Civil Engineering and Architecture, Wuhan University of Technology, Wuhan 430074, China \\ ${ }^{2}$ School of Civil and Environmental Engineering, Nanyang Technological University, Singapore 639798 \\ Correspondence should be addressed to Zhiyong Yang; zyyang@whut.edu.cn
}

Received 25 June 2018; Accepted 9 October 2018; Published 23 October 2018

Academic Editor: Jose A. Lozano-Galant

Copyright (c) 2018 Liang Zhao et al. This is an open access article distributed under the Creative Commons Attribution License, which permits unrestricted use, distribution, and reproduction in any medium, provided the original work is properly cited.

\begin{abstract}
There is a growing demand for silos with large diameters and volumes; hence, the stresses induced by the temperature differences between the inner and the outer surfaces of the concrete walls of the large silos become significant. Sunshine is the main source of the temperature differences; and it is necessary to investigate the influences of sunshine on large concrete silos and ensure their safety and durability. In this paper, the temperature distribution of a concrete silo exposed to the sunshine was measured on site. A finite element (FE) model was built to analyze the temperature distribution under the sunshine, and the FE model was validated by comparing the yielded temperature field with that obtained on site. Based on the temperature field yielded in the FE model, the internal forces of the silo were determined by performing a structural analysis. After that, the FE model was extended and used for a parametrical study, and the influences induced by the factors like meteorological parameters, dimension of silos, and reference temperature on the temperature effects of the silo were investigated. The simulation results showed that the temperature gradient exhibited significant nonlinearities along the wall thickness. The performance of a steady-state analytical method was evaluated, which is conventionally used for the design of silos. It was found that, for the silos with the thicknesses of more than 30 centimeters, the steady-state method overestimated the temperature effects. It is suggested here that nonlinear temperature gradients should be employed for considering the temperature effects of large silos.
\end{abstract}

\section{Introduction}

Large-diameter concrete silos are sensitive to environmental conditions, e.g., temperature stresses induced by sunshine and the high temperature stored material. The traditional steady-state analytical method is user-friendly and usually adopted to calculate for a conventional structural design. However, for an open-air concrete structure, its daily varying temperature field is quite complex while being exposed to a time-dependent thermal environment $[1,2]$. With the demands for capacities of the silos, the diameters and wall thicknesses of silos become large and the temperature gradients between inner and outer surfaces of the silo walls are severe under solar radiation and high temperature stored material. The safety and reliability of silos, consequently, decreased by the temperature effects $[3,4]$. Accurate determinations of the non-uniform temperature fields and internal forces of the silos are of great importance in the design and construction processes.
Previous studies on the non-uniform temperature field mainly focused on the temperature effects of bridges [58]. Few studies were conducted to evaluate the steel silos under solar radiation $[9,10]$. Regarding concrete silos, the pressure of stored material is always the first concern in the design [11-15]. Recently, the effects of temperature variations of the stored material on silos attracted the attention of scientists. However, most of the researches focused only on those silos of relatively with diameters of no more than 20 meters [16-18]. Jiang et al. [19] measured temperatures of a grain silo, and then they compared the results of the FE simulations with the measured temperature field. Kong et al. [20] calculated the internal force of silo under the seasonal temperature differences as well as the internal and external temperature difference with a steady-state calculation method. The results showed that the hoop force generated by the temperature difference of the silo was $6 \sim 8 \%$ of the maximum static pressure imposed by the stored material. More recently, based on the temperature field that measured 
experimentally, Lapko et al. [21, 22] investigated the hoop thermal stresses and bending moments in reinforced concrete silo battery subjected to grain pressure and thermal gradient with numerical FEM. Chen et al. [23] concluded that the hoop thermal stress caused by temperature difference was around $55 \%$ of that imposed by the coal load. Lippold [24] pointed out that transient thermal stresses caused by the solar radiation increased the compression stressed due to posttensioning, with causes very high transverse tensile stresses in the outer wall. Furthermore, Chen et al. [25] performed an experimental study and 3D FE simulations on a reinforced concrete silo. The silo has a diameter of 136.5 meters and a height of 19.35 meters; the effects of sunshine temperature patterns, seasonal temperature patterns, and the drop of temperature were studied.

A traditional steady-state method is often used in the studies mentioned above. The method assumes a linear temperature gradient along the wall thickness in the determinations of the temperature effects of silos. To the best of the authors' knowledge, very few researches adopted transient method for investigating the temperature effects of largediameter concrete silos under sunshine. While under solar radiation, the temperature gradients along the wall thickness of silos are nonlinear. The performance of the traditional steady-state method, consequently, should be evaluated while being used for design large-scale silos.

In this paper, the temperature distribution of a largediameter silo under solar radiation was measured on site, and influences of the temperature difference on the silo were studied numerically. The non-uniform temperature effects are compared with results obtained with the traditional steady-state analysis method. Finally, main factors [26] of temperature effects are also determined, which provides references for the structural design of large-diameter concrete silos.

\section{Thermodynamic Analysis Theory}

2.1. External Boundary Condition. In a natural environment, three thermal conditions affect silos including the solar shortwave radiation, radiation from surroundings and the thermal convection. Thus, the thermal boundary condition for the outer surface of silos can be expressed by [27]

$$
\left.\lambda \frac{\partial T}{\partial n}\right|_{\Gamma}=q_{s}+q_{c}+q_{r}
$$

where $\lambda$ is the thermal conductivity $[\mathrm{W} /(\mathrm{m} \cdot \mathrm{K})] ; \Gamma$ is the cross-sectional boundary; $n$ is the outward normal vector; $q_{\mathrm{s}}, q_{\mathrm{c}}$, and $q_{\mathrm{r}}$ denote the heat flux through into the inner surface by solar radiation, heat convection, and heat transfer, respectively $\left[\mathrm{W} / \mathrm{m}^{2}\right]$.

Solar shortwave radiation is divided into three categories: a direct solar radiation, a scattered radiation, and a reflection radiation. Since normal vectors of silo surface and ground surface are parallel to each other, the total solar radiation heat flux $q_{\mathrm{s}}$ obtained in the outer surface of silo can be expressed by $[8,27]$

$$
\begin{aligned}
q_{s} & =A_{s}\left[\left(\cos \theta+0.5 r_{e} \sin \beta\right) \cdot 0.9^{t_{u} k_{a} m} I_{0}\right. \\
& \left.+0.5\left(1+r_{e}\right)\left(0.271-0.294 \cdot 0.9^{t_{u} k_{a} m}\right) I_{0} \sin \beta\right]
\end{aligned}
$$

where $A_{\mathrm{s}}$ is the absorption of solar radiation; $\theta$ is the solar incident angle on the vertical surface $\left[^{\circ}\right] ; \beta$ is the solar altitude angle $\left[{ }^{\circ}\right] ; r_{\mathrm{e}}$ is the ground short-wave reflectivity; $I_{0}$ is the solar radiation intensity at the upper limit of the earth's atmosphere $\left[\mathrm{W} / \mathrm{m}^{2}\right] ; t_{\mathrm{u}}$ is an atmospheric turbidity factor; $k_{\mathrm{a}}$ is relative atmospheric pressure; $m$ is an atmospheric optical mass corrected by air pressure.

According to Newton's Law of Cooling, the convective heat flux $q_{c}$ between the surface and air can be calculated as $[8,27]$

$$
q_{c}=h_{c}\left(T_{a}-T\right)
$$

where $T_{\mathrm{a}}$ is the air temperature $\left[{ }^{\circ} \mathrm{C}\right]$ and $h_{\mathrm{c}}$ is the convective heat transfer coefficient.

The heat flux of the radiative heat transfer $q_{\mathrm{r}}$ can be obtained as $[8,27]$

$$
q_{r}=C_{s} \varepsilon\left[\varepsilon_{a}\left(T_{a}+273\right)^{4}-(T+273)^{4}\right]
$$

where $C_{\mathrm{s}}$ is Stefan-Boltzmann's constant; $\varepsilon$ is the concrete surface emissivity; $\varepsilon_{\mathrm{a}}$ is the atmospheric long wave radiation rate.

2.2. Internal Boundary Condition. The silo can be considered as a completely closed space when it is empty. Therefore, a surface comprehensive heat transfer coefficient is adopted for the convective heat and the radiative heat transfer. Thus, the boundary conditions are as follows [8]:

$$
\left.\lambda \frac{\partial T}{\partial n}\right|_{\Gamma}=h_{2}\left(T_{a}^{\prime}-T\right)
$$

where $h_{2}$ is the surface comprehensive heat transfer coefficient; $T_{a}^{\prime}$ is the inside air temperature $\left[{ }^{\circ} \mathrm{C}\right]$.

The temperature field becomes complex for high temperature stored material when the silo is full. Therefore, simplifications are made for the thermal boundary conditions. A wall thickness of the storage unit first is established to simulate the interaction between the stored material and the wall. Further, the storage layer and the silo wall have a good contact, so the inner wall of the material stored layer can be considered as the first boundary condition [20]:

$$
\left.\lambda \frac{\partial T}{\partial n}\right|_{\Gamma}=T_{\mathrm{n}}
$$

where $T_{\mathrm{n}}$ is the temperature of the stored material $\left[{ }^{\circ} \mathrm{C}\right]$.

\section{Experimental Investigation of Temperature Field}

3.1. Description of Experimental Test. This project presents a large-diameter cement clinker silo, which belongs to Junwang 


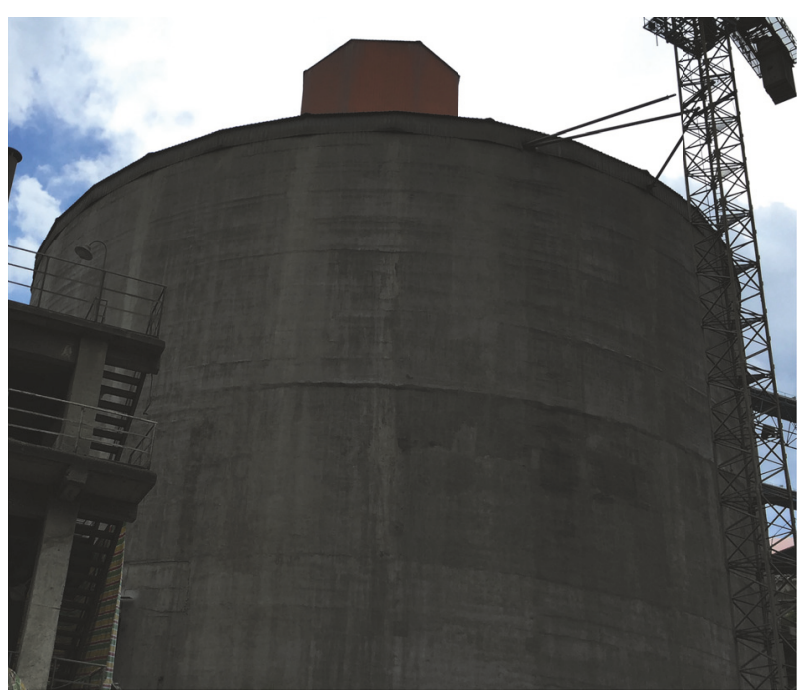

(a)

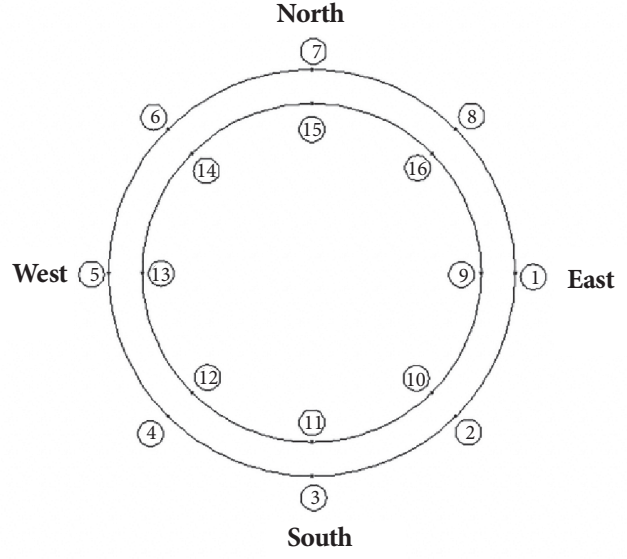

(b)

FIgURE 1: No.1 clinker silo of Junwang cement co. ltd. (a) Photo of clinker silo. (b) Layout of measured points.

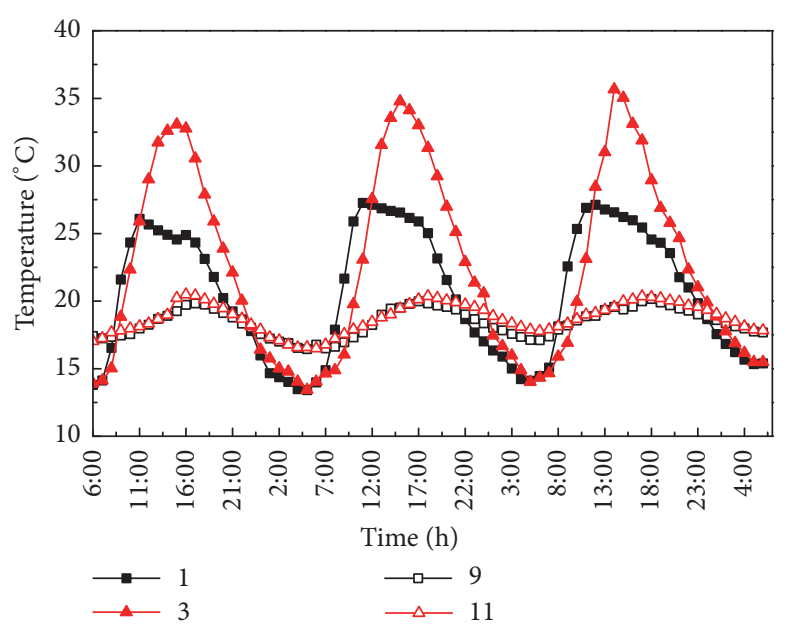

(a)

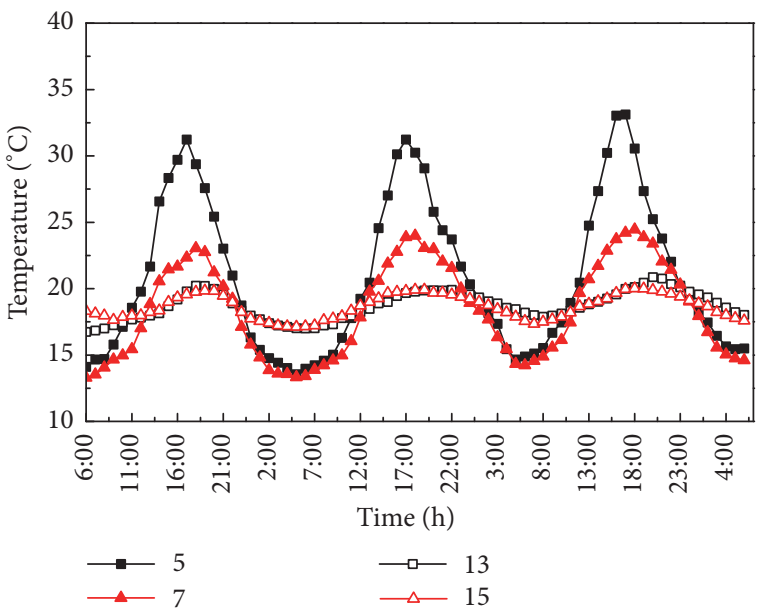

(b)

FIGURE 2: Temperature curve of each measured point on the wall in case of the empty silo. (a) Temperatures of measured points on the east and the south walls. (b) Temperatures of measured points on the west and the north walls. $(1,3,5,7,9,11,13$, and 15, temperature measured points (see Figure 1(b))).

Cement Limited Corporation in Hubei province, China. The height of the silo is $23.38 \mathrm{~m}$, the diameter is $46.4 \mathrm{~m}$, and the wall thickness is $0.8 \mathrm{~m}$ (see Figure 1(a)). The on-site measurements were taken intermittently from October 2015 to March 2016. It is noteworthy that digital temperature sensors type DS18B20 were used to measure the temperature. During the measurements, a temperature data collector was adopted, and a time interval of one hour was selected.

References $[27,28]$ showed that the temperature variation along the height of concrete hollow structures such as circular hollow piers, chimneys, and large cable towers which are similar to the silo structure is within $1^{\circ} \mathrm{C}$. The temperature distribution along the height of the silo can be approximately considered to be uniform. In this paper, the cross-section at the height of $7 \mathrm{~m}$ was selected for the measurements. The sensors were located at intervals of $45^{\circ}$ along the perimeter of the silo wall (see Figure 1(b)). Further, measured points $1 \sim 8$ were located on the outer surface of the silo wall, and the measured points $9 \sim 15$ were located on the inner surface. Furthermore, two loading cases were investigated based on the working conditions of the silo, where Case 1 is the case when the silo is empty, while Case 2 is the case when the silo is full.

3.2. Temperature Field Analysis in Case of Empty Silo. The measurements were taken before the silo was in use. 72 hours of continuous time (6: 00 on 14th October to 6: 00 on 17 th October) were selected for a continuous measurement. Figure 2 shows the temperature variations of the silo wall against time in the east, south, west, and north directions, 


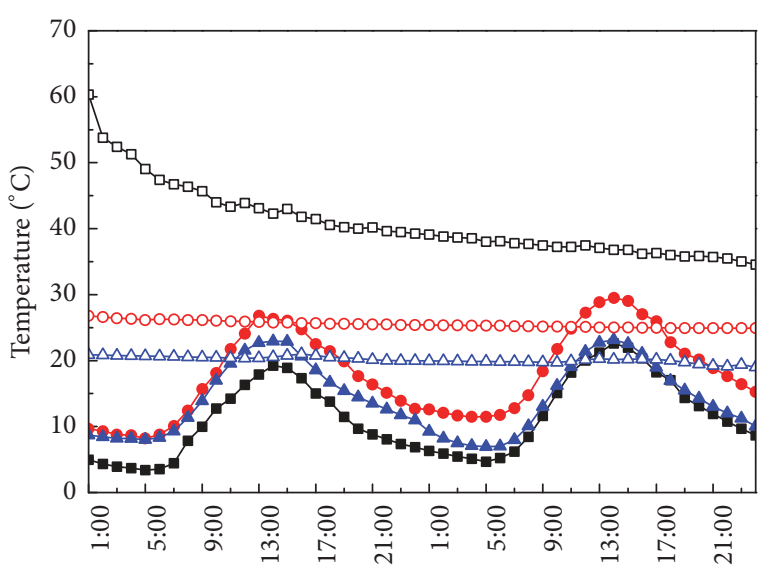

Time (h)

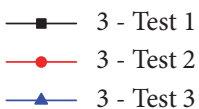

$\longrightarrow 3$ - Test 3

(a)



Time (h)

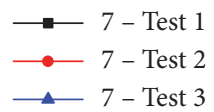

$\longrightarrow 15-$ Test 1

$\longrightarrow 15$ - Test 2

$\longrightarrow-15-$ Test 3

(b)

FIGURE 3: Temperature curve of each measured point on the wall in case of the full silo. (a) Temperatures of the points on the south wall. (b) Temperatures of the points on the north wall.

respectively. It can be seen clearly that the temperature is changing periodically day and night. The temperature of the outer surface of the wall is mainly affected by the air temperature and solar radiation. Because of the solar radiation, temperature differences between the outer surface at different azimuth angles are different at the same time and the maximum circumferential temperature difference in one day has reached $12.32^{\circ} \mathrm{C}$. Due to the influence of the air temperature inside of the silo, temperatures at each measured point on the inner surface of the wall change insignificantly during the day. The measured air temperature in the silo is $2^{\circ} \mathrm{C}$ $\sim 3^{\circ} \mathrm{C}$ higher than that out of the silo. This finding is consistent with that in case of the chimney and circular hollow pier $[27,28]$.

3.3. Temperature Field Analysis in Case of Full Silo. A clinker was continuously cooled through a cooler before getting into the silo, and then it was covered by a new clinker during the production. Hence, it was difficult to record the real-time temperature of the clinker reserves. Instead, the temperature was recorded at about $7 \mathrm{~m}$ intervals in each stack till it being fully loaded. The measuring time was on 10th March and 11th March (Test 1), 18th March and 19th March (Test 2), and 25th March and 26th March (Test 3). Figure 3 shows the variation of the temperature against time. Four points were selected: point 3 and point 11 in the south and point 7 and point 15 in the north.

It can be seen from Figure 3 that measured points on the outer surface of concrete wall show similar variation trends of temperature with those of the Case 1, which indicates that the temperature of the outer surface is mainly affected by the external environment. On the contrast, the temperature of the inner surface is mainly affected by the temperature of clinker. The inner surface temperature in the Test 1 reaches $50^{\circ} \mathrm{C} \sim 60^{\circ} \mathrm{C}$ when the clinker has just reached the measurement section. The temperature of the point 15 is lower than the temperature of the point 3 at 1:00 since the clinker is distributed nonuniformly in the silo and an incomplete contact takes place between the clinker and the inner surface of the wall. As the clinker fills in the silo continuously, the clinker filled in earlier is under pressure, and hence the contact between the clinker and the inner surface improves. This is why the temperature of point 15 increases at 3:00, and a significant fluctuation is presented here. The inner surface temperature changes rapidly in the early time - a significant drop of $27^{\circ} \mathrm{C}$ is presented on 11th March. With the passage of time, the inner surface temperature decreases slowly. After 10 days, the temperature at the test section drops only around $2^{\circ} \mathrm{C}$ in the 11th day. The temperature of the inner surface in Test 3 drops around $1^{\circ} \mathrm{C}$ in one day. Till then, the temperature of the test section reaches a steady state when the clinker is piled up in the silo.

3.4. Analysis of Temperature Difference. The temperature variation in structures includes two aspects: the overall temperature change and the inner temperature difference of the structure. $[20,25,29]$ claimed that temperature differences between the outer and inner surfaces of the wall act a major role in the temperature effects of the silos. Therefore, the temperature difference between the outer and inner surfaces of the silo wall is discussed here. The temperature difference is defined as positive when the outer surface temperature is higher than the inner surface temperature, the temperature difference is negative otherwise. Figure 4 presents the temperature difference against time. It can be observed from Figure 4(a) that there are significant differences between the maximum positive temperature differences of different orientations. It is generally about 0 to 1 hour before the occurrence of the maximum temperature of the outer surfaces. Temperature differences of the east wall and the north wall 


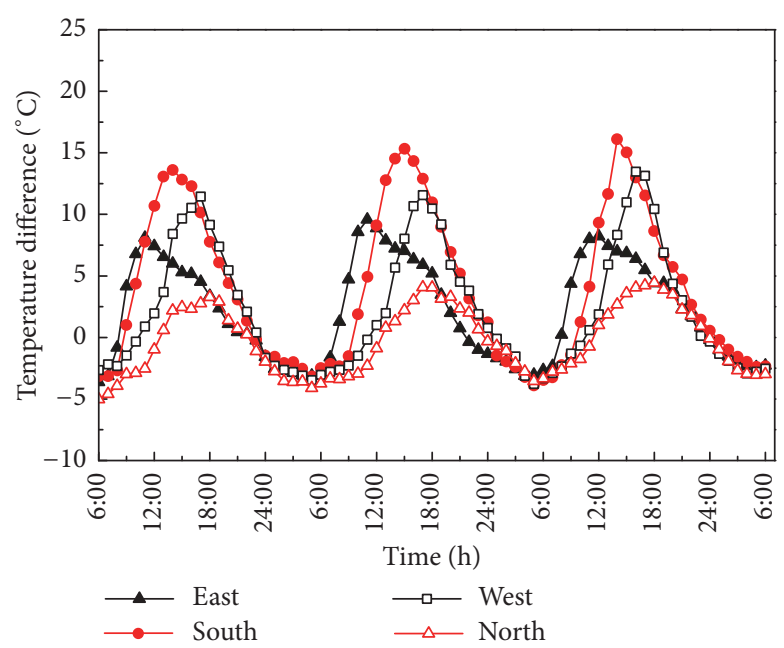

(a)

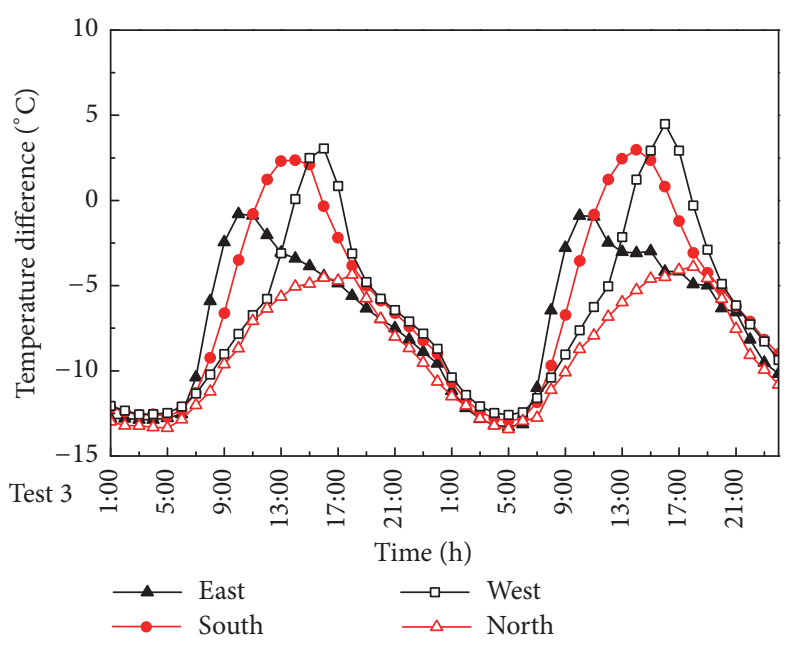

(b)

Figure 4: Temperature difference in function of time. (a) Case 1. (b) Case 2.

are minor, while those of the south wall and the west wall are large. The maximum negative temperature differences of each wall are the same; see the curves at 5: 00. The circumferential temperature difference is small and can be neglected at that moment. The temperature difference of each section is not obvious at 22: $00 \sim 23: 00$, and the temperature distribution of each section is uniform where the differences are between $0.13^{\circ} \mathrm{C}$ and $1.93^{\circ} \mathrm{C}$.

It can be seen from Figures 3 and 4(b) that negative temperature differences are large in Test 1 , which reach $-57.65^{\circ} \mathrm{C}$ when clinker reaches the test section. It is worth mentioning that there are no positive temperature differences. At the early stage, due to the large rate of the heat dissipation between the clinker and the external environment through the silo wall and the roof, the negative temperature difference decreases to around $-33^{\circ} \mathrm{C}$ after 24 hours. With the passage of time, the temperature differences become stable in Test 2 , and the variations are within $2^{\circ} \mathrm{C}$. Test 3 , measured on 25 th March and 26th March, shows that the temperature differences at the same time of the day are within $1^{\circ} \mathrm{C}$. It can be seen that when the silo is fully loaded, the temperature of clinker tends to be a constant in the test section and the maximum temperature differences on each azimuth wall change insignificantly. The occurrence time of the maximum temperature difference of each azimuth wall is basically the same with that of the Case 1.

\section{Numerical Simulation of Silo Temperature Field}

4.1. Model Establishment and Verification. Numerical simulations contained the analyses of non-uniform temperature distribution and temperature stresses by using a finite element program of ANSYS. As the first step of building the model, SOLID 90 element was used to determine the temperature field. This element is a 20-node thermal element with a single degree of freedom of temperature, at each node, which

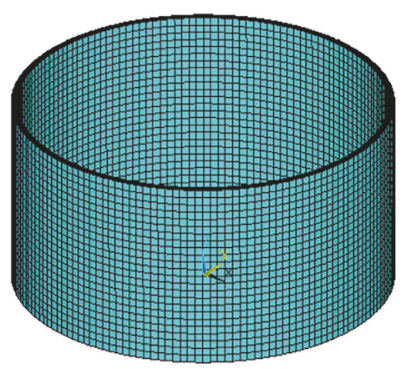

FIgURE 5: The EF model.

is capable of performing steady-state or transient thermal analyses. Compared with shell elements, SOLID 90 element is more accurate for temperature field analyses. Further, the temperature variations along the thickness of the silo wall can be presented by using SOLID 90. Furthermore, assumptions were made to build the model: (1) the building above top of silo and the wall of the bucket were neglected in the numerical model since their influences on the stresses of the silo were deemed minor and can be neglected; (2) a consolidation of the bottom of the silo wall was assumed in the numerical model; (3) temperature was not coupled with stress and deformation, which means the influences of deformations caused by temperature variations on the stresses of the silo were not considered. Finally, the FE model is shown in Figure 5.

Material properties of the silo are shown in Table 1. Concrete properties were obtained with experiments. As the clinker is the same as that in literature [30], parameters of clinker were referred to [30]. The simulation results of Case 1 were compared with results measured on 16th October, 2015. The simulation results of Case 2 were compared with the measured data on 25th March, 2016. 


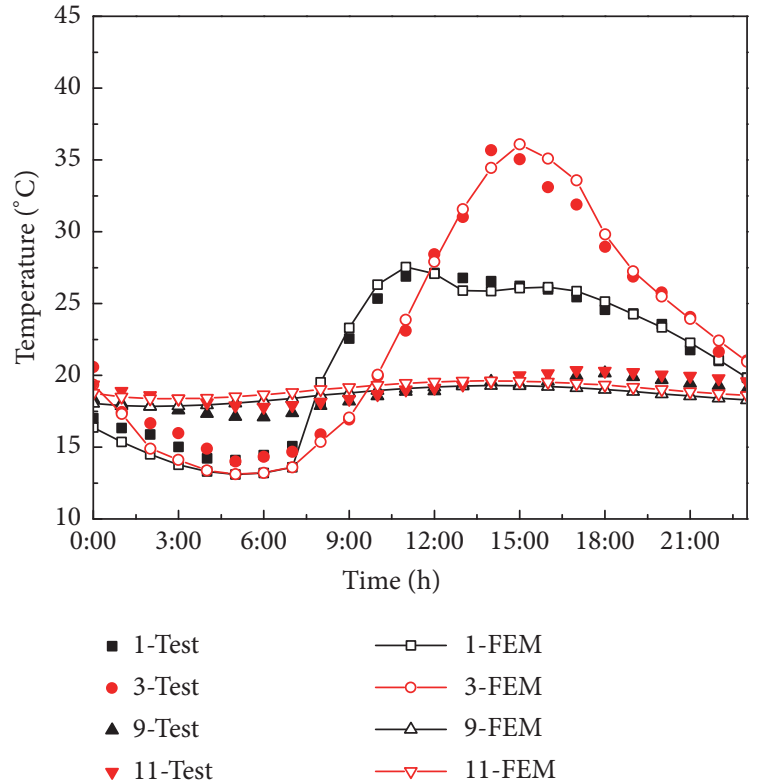

(a)

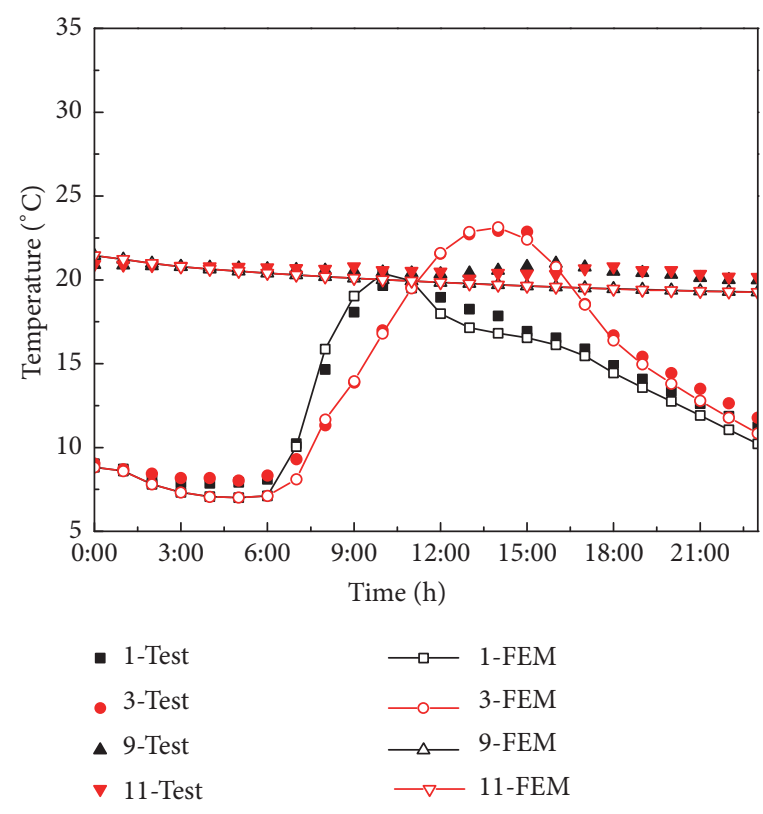

(b)

Figure 6: Comparison of temperature changes at measured points. (a) East and south points of Case 1. (b) East and south points of Case 2.

TABLe 1: Properties of materials adopted in the present study.

\begin{tabular}{lccc}
\hline Materials & Density $\left(\mathrm{kg} \cdot \mathrm{m}^{-3}\right)$ & Specific heat $\left(\mathrm{J} \cdot \mathrm{kg}^{-1} \cdot \mathrm{K}^{-1}\right)$ & Thermal conductivity $\left(\mathrm{W} \cdot \mathrm{m}^{-1} \cdot \mathrm{K}^{-1}\right)$ \\
\hline Concrete & 2400 & 960 & 1.74 \\
Clinker & 1200 & 840 & 0.29 \\
\hline
\end{tabular}

TABLE 2: Comparison of temperature differences of Case 2 and Case 3 at different time.

\begin{tabular}{lcccccccc}
\hline \multirow{2}{*}{ Orientation } & \multicolumn{2}{c}{$5: 00$} & \multicolumn{2}{c}{$11: 00$} & \multicolumn{2}{c}{$14: 00$} & \multicolumn{2}{c}{$16: 00$} \\
& Case 2 $\left[{ }^{\circ} \mathrm{C}\right]$ & Case 3 $\left[{ }^{\circ} \mathrm{C}\right]$ & Case 2 $\left[{ }^{\circ} \mathrm{C}\right]$ & Case 3 $\left[{ }^{\circ} \mathrm{C}\right]$ & Case 2 $\left[{ }^{\circ} \mathrm{C}\right]$ & Case 3 $\left[{ }^{\circ} \mathrm{C}\right]$ & $\mathrm{Case} 2\left[{ }^{\circ} \mathrm{C}\right]$ & $\mathrm{Case} 3\left[{ }^{\circ} \mathrm{C}\right]$ \\
\hline East & -13.50 & -6.51 & -0.74 & 6.61 & -1.71 & 3.57 & -3.45 \\
South & -13.51 & -6.34 & -0.87 & 6.27 & 3.28 & 10.02 & 1.22 \\
West & -13.50 & -6.43 & -6.75 & -0.94 & 0.60 & 6.53 & 4.44 & 10.72 \\
North & -13.50 & -6.32 & -6.67 & -0.74 & -3.79 & 1.53 & -4.81 \\
\hline
\end{tabular}

The time-dependent temperature of the non-uniform temperature field under solar radiation was achieved with FE models for the both cases. Besides, a comparative study between measured results and numerical simulations was conducted, and the results are shown in Figure 6. It is observed that the maximum temperature difference between measured results and numerical simulations is $2^{\circ} \mathrm{C}$, and the error of numerical simulation results is $8.70 \%$, while the minimum difference between them is $0.2^{\circ} \mathrm{C}$. Numerical simulation results are in a good agreement with the measured results; consequently, the numerical model was further used for determining the temperature effects of the silo.

4.2. Temperature Filed Analysis. Case 3 was defined here as the empty silo on 25th March, 2016. The temperature of the silo under Case 2 was determined and compared with that of the silo under Case 3. This was to present differences of the temperature fields in case of the empty silo and the full silo at the same day. Table 2 shows temperature differences of silo walls in four directions at different times. The maximum positive temperature difference occurred at 16: 00. At that moment, due to the influences of the clinker temperature, the maximum positive temperature difference of Case 2 is lower than that of Case 3 by around $6.28^{\circ} \mathrm{C}$. The maximum negative temperature difference of Case 3 is about $7.18^{\circ} \mathrm{C}$ higher than that of Case 2. It is worth noting that the maximum negative temperature difference occurs in case of the full silo, and the maximum positive temperature difference happens in case of the empty silo.

The temperature distribution along the wall thickness is shown in Figure 7. It is seen that temperature variations along the wall thickness exhibit significant nonlinearities. Further, influences of the air temperature and periodic change of solar radiation on the temperature field of the silo are significant only within the thickness of $50 \mathrm{~cm}$ from the outer surface to the inner surface of the silo wall. Furthermore, times of the 


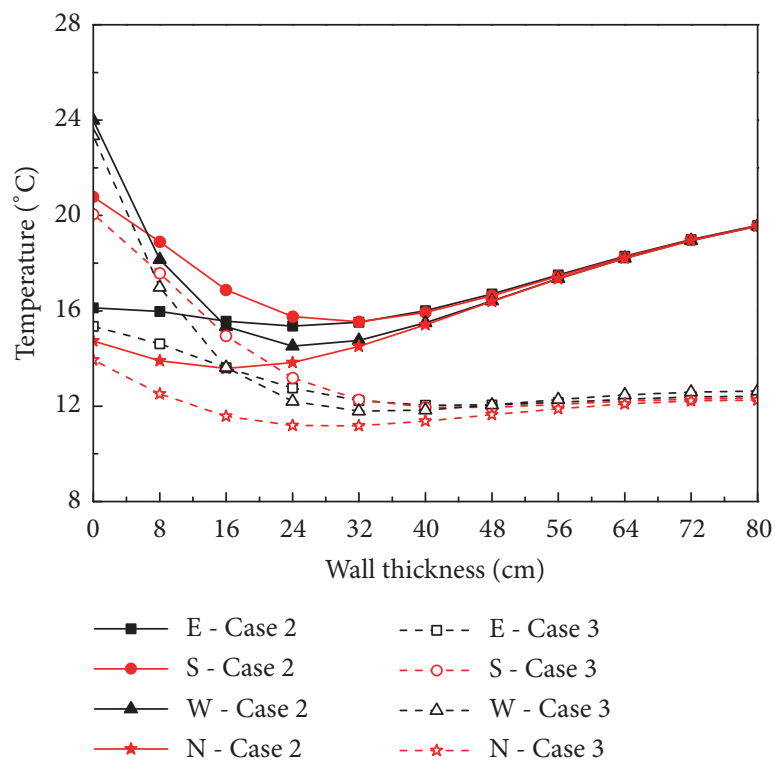

(a)

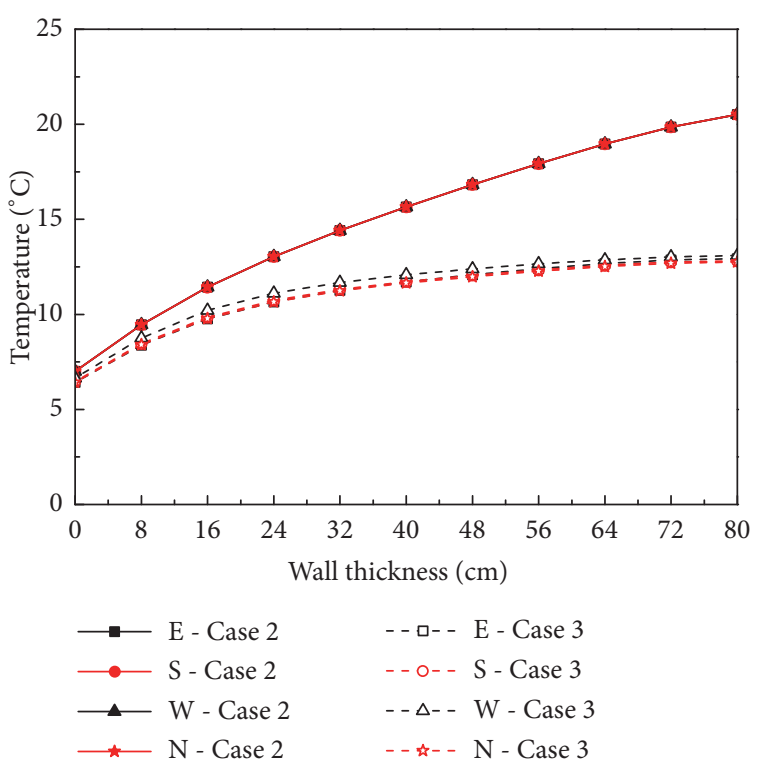

(b)

FIgURE 7: Temperature along the thickness of each azimuthal wall. (a) Time of maximum positive temperature difference. (b) Time of maximum negative temperature difference.

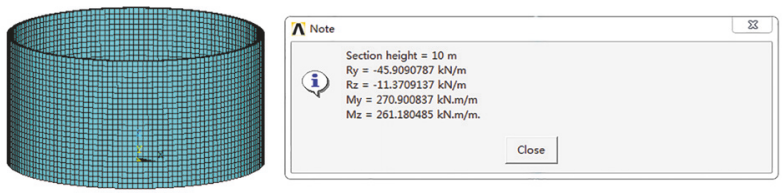

FIGURE 8: Internal forces of silo wall at any height.

occurrence of the maximum negative temperature differences at different directions are close, magnitudes of these temperature differences are the same, and the temperature variation trends along the wall thickness at different directions are similar, showing significant nonlinearities. Hence, it can be considered that the temperature gradients are approximately axisymmetric at this time.

\section{Temperature Effect of Silo under Solar Radiation}

5.1. Analysis of Temperature Effect. Based on temperature fields of Case 2 and Case 3, temperature stresses of silo were obtained by performing structural analyses, and a SOLID 90 element was replaced by SOLID 95 element in the numerical model. The SOLID 95 element only indicates stresses as outputs. In shell structures, however, the resultant force per unit height and combined the torque is always used instead of simply adopting the stress. Therefore, another program was developed to transform stresses in the solid element to internal forces of the whole silo in this paper, which facilitates the design and the reinforcement calculation. Figure 8 shows how internal forces can be displayed by the software such as the hoop force $R_{y}$, the vertical force $R_{z}$, the circumferential moment $M_{y}$, and the vertical moment $M_{z}$ at any height of the silo wall.

In order to investigate the relationship of the internal force of silo subjected to the pressures of the stored material and its temperature action, the horizontal pressure caused by the fully loaded stored material was also analyzed in this section, named as Case 4. The SOLID 95 was adopted here. Further, assumptions were made: (1) the reinforcements in the silo were neglected in the model; (2) the boundary condition of the silo at the bottom end was assumed to be a consolidation; (3) the friction of the stored material on the wall was neglected in the analyses $[29,30]$. Furthermore, at the top of stored material or at a distance $s \mathrm{~m}$ below the center gravity of the silo, the pressures of the stored material pressures $p_{\mathrm{h}}$ imposed on the unit area of the silo wall should be calculated as

$$
\begin{aligned}
p_{h} & =k \gamma s \\
\mathrm{k} & =\tan ^{2}\left(45^{\circ}-\frac{\phi}{2}\right)
\end{aligned}
$$

where $k$ is lateral pressure coefficient, $\phi$ is internal friction angle of stored material $\left[^{\circ}\right], \phi=33^{\circ}, \gamma$ is the density of stored material $\left[\mathrm{kN} / \mathrm{m}^{3}\right]$, and $\gamma=16 \mathrm{kN} / \mathrm{m}^{3}$.

Internal forces are shown in Figures 9 and 10 against wall height, respectively. It can be seen that $\mathrm{R}_{\mathrm{z}}$ is close to zero along the silo wall in both cases, which can be neglected. Overall, internal forces of Case 2 are greater than those of Case 3 at the occurrence of maximum negative temperature difference $\left(\Delta t_{\text {max neg }}\right)$. Because the overall temperature decline of case 3 is significant than that of Case $2, \mathrm{R}_{\mathrm{y}}$ of Case 3 at the bottom 

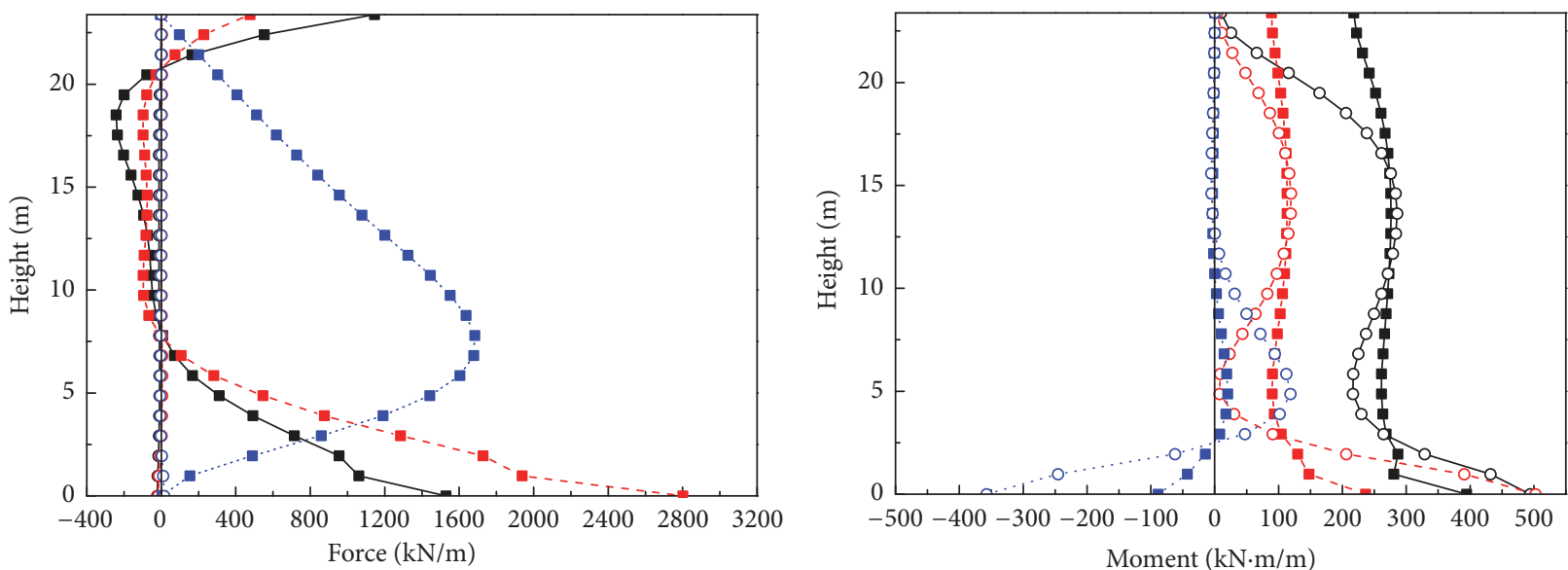

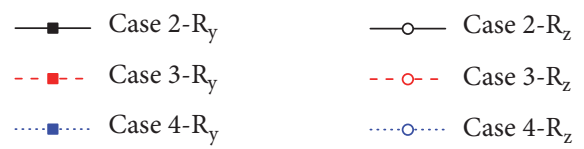

(a)

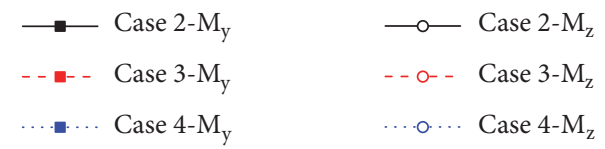

(b)

FIGURE 9: Distributions of internal forces at $\Delta t_{\text {max,neg }}$ (east wall). (a) The forces $R_{y}$ and $R_{z}$. (b) The bending moments $M_{y}$ and $M_{z}$.

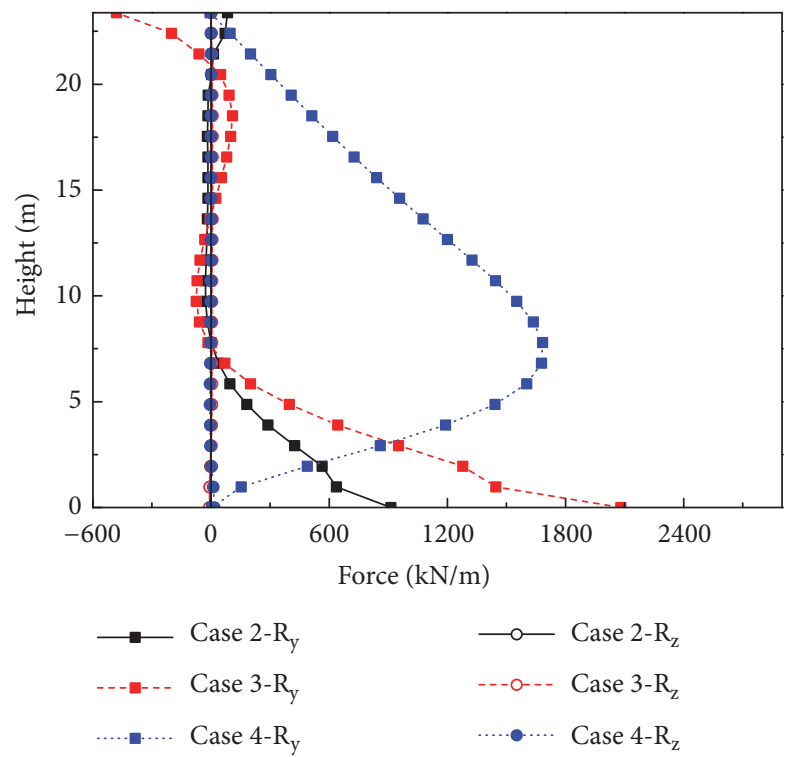

(a)

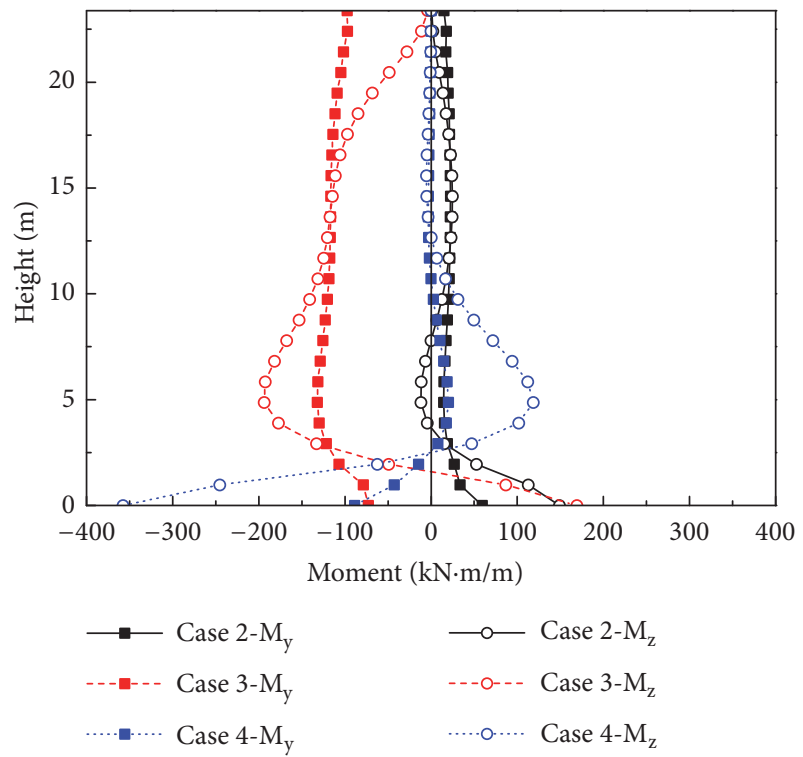

(b)

Figure 10: Distributions of internal forces at $\Delta t_{\text {max,pos }}$ (west wall). (a) The forces $R_{y}$ and $R_{z}$. (b) The bending moments $M_{y}$ and $M_{z}$.

of the silo is larger than that of Case 2 (see Figure 9(a)). Since the prestressed and nonprestressed steel bars of this section are sufficient to resist internal forces, internal forces of Case 3 at $\Delta t_{\text {max nen }}$ were not be considered in the design. Hence, it can be concluded that Case 2 is more severe than Case 3.

Bending moments of Case 3 are negative along the height of the silo wall at the occurrence of maximum positive temperature difference $\left(\Delta t_{\max , \text { pos }}\right)$ (see Figure 10). Reinforcements inside of the concrete wall are configured symmetrically, and they are subjected to a large solar radiation intensity; it is necessary to consider large negative bending moments induced by large temperature differences because an excessive tensile stress of the inner surface could lead to cracking of the inner wall in case of the empty silo.

A comparison was made between Case 2 and Case 4. It can be seen from Figure 9 that $R_{y}$ generated by the stored material is relatively large in the region of above $5 \mathrm{~m}$ of the silo wall, where $\mathrm{R}_{\mathrm{y}}$ generated by the temperature differences in that region can be neglected. The silo wall is only subjected to $\mathrm{M}_{\mathrm{y}}$ generated by the temperature difference; therefore, 


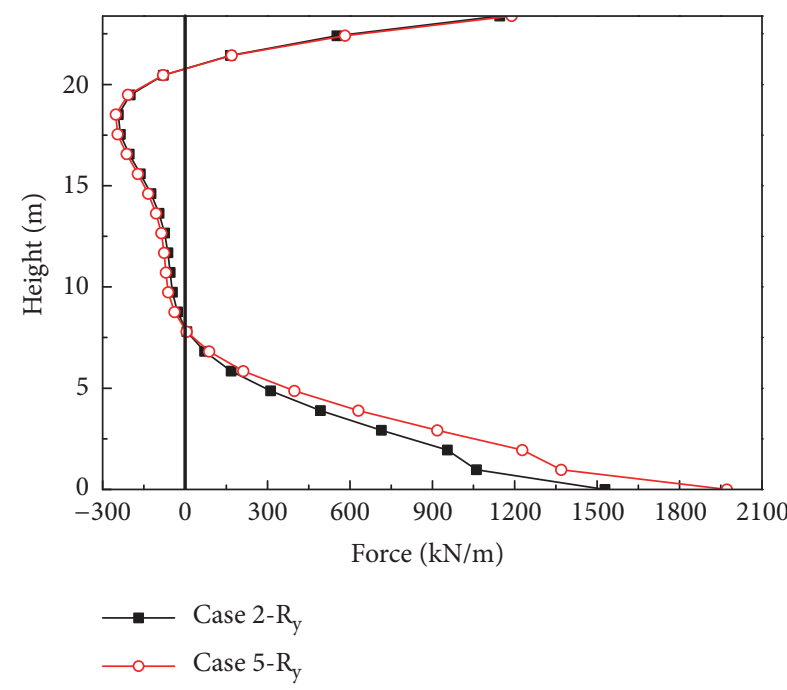

(a)

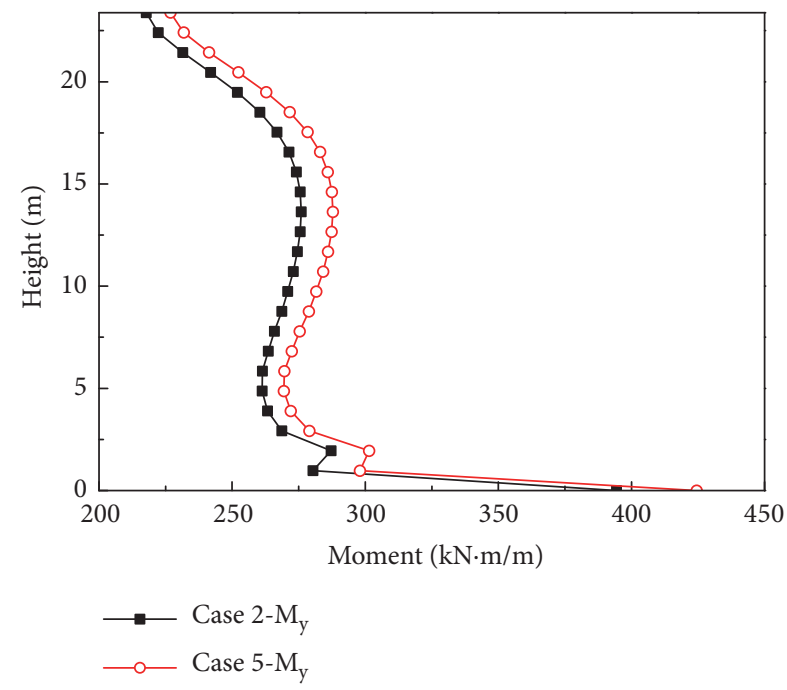

(b)

FIGURE 11: Distributions of internal forces at $\Delta t_{\text {max,neg }}$ (east wall). (a) The hoop force $\mathrm{R}_{\mathrm{y}}$. (b) The circumferential moment $\mathrm{M}_{\mathrm{y}}$.
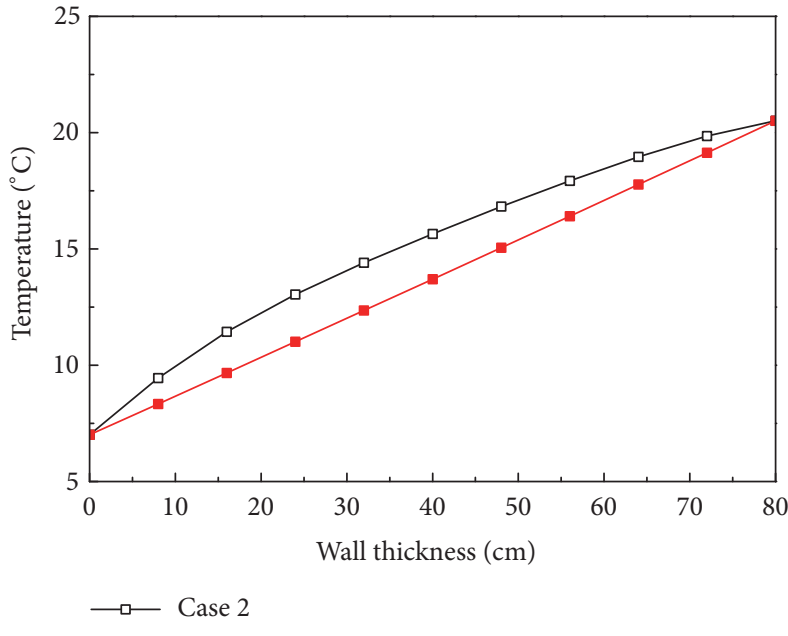

(a)

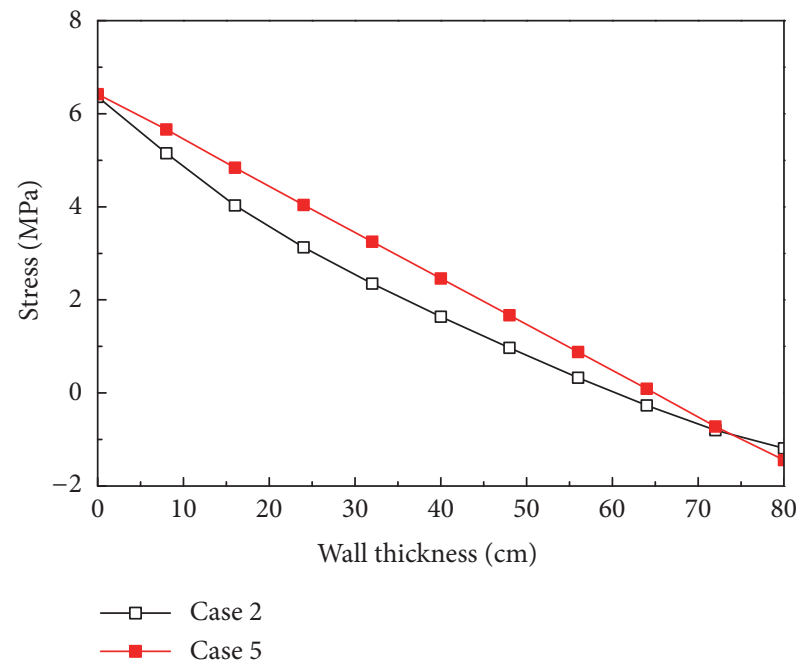

(b)

Figure 12: Distributions of temperature and hoop thermal stresses along the silo wall at $\Delta t_{\text {max,neg. }}$ (a) Temperature distribution. (b) Hoop thermal stresses distribution.

$\mathrm{M}_{\mathrm{y}}$ considering the influence of concrete creep is usually converted into an equivalent hoop force $\mathrm{R}_{0}$ in the design [29]. Further, the distribution of hoop thermal stresses along the wall thickness is obtained with a FE calculation. It is noted here that the hoop thermal stresses consist of two parts: the first part is the uniform stresses caused by hoop force and the second part is the non-uniform stresses caused by circumferential bending moment, among which the $\mathrm{R}_{0}$ can be obtained by integrating the non-uniform stresses in this part. $f_{\max }$ is the ratio of the maximum $\mathrm{R}_{0}$ considering the concrete creep to the maximum $\mathrm{R}_{\mathrm{y}}$ caused by the stored load $[20,29]$. The value of $f_{\max }$ is $28.55 \%$ in Case 2 , which is much higher than the limit value of $8 \%$ provided in GB50077-2003 [29] (see Figure 13).
The temperature effects in case of the full silo (defined as Case 5) were determined by using the conventional analytical method of the steady-state without considering the effects of solar radiation. The negative temperature difference obtained here is $-13.50^{\circ} \mathrm{C}$. Internal forces and the distribution of the temperature as well as hoop thermal stresses of Case 2 and Case 5 are shown in Figures 11 and 12, respectively.

It can be seen from Figure 11 that internal forces of Case 5 are greater than those of Case 2. Further in Figure 12, the temperature and hoop thermal stresses are nonlinear distribution along the thickness of the wall (Case 2), while the results of the Case 5 are distributed linearly. Hence, even if the temperature difference is same, numerical simulation results obtained with the transient method are much smaller 


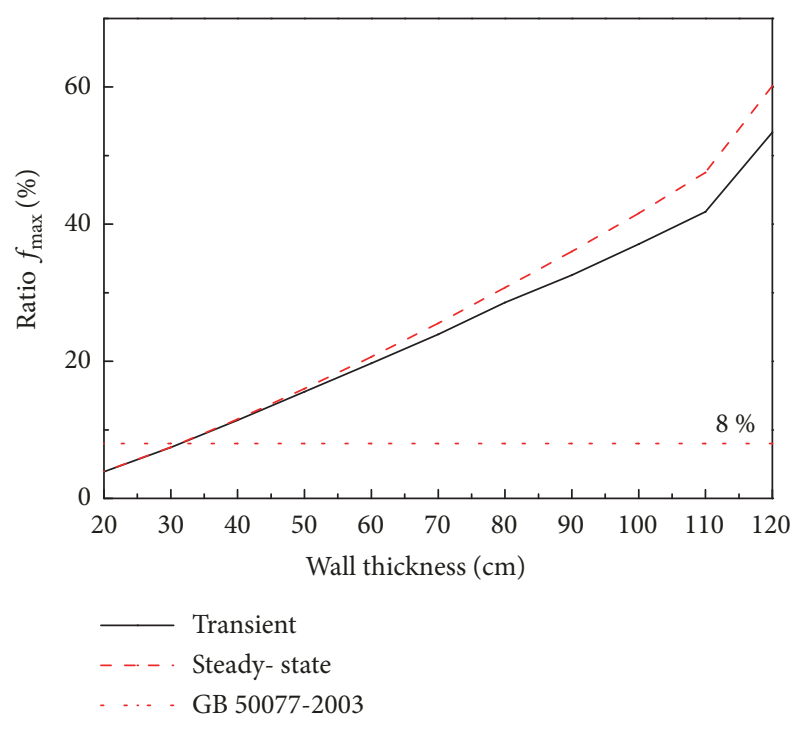

FIgURE 13: Ratio $f_{\max }$ in case of different wall thickness.

than those with the traditional steady-state method. Because the temperature distribution obtained with transient method could reflect better the change of silo temperature with the time in whole day, the internal forces obtained with transient method are closer to the reality.

Furthermore, in order to analyze the influence of different analytical methods on numerical simulations, Case 2 was taken as the basic model; the transient and the steady-state methods were used to calculate the temperature effects when the wall thickness varying from $20 \mathrm{~cm}$ to $120 \mathrm{~cm}$. Moreover, internal forces of the silo wall under the maximum negative temperature difference were obtained. Figure 13 shows the ratio $f_{\max }$ as a function of wall thickness with the transient and the steady-state methods, respectively. The ratios $f_{\max }$ obtained with these two methods are similar in case of the wall thickness no more than $30 \mathrm{~cm}$, which is basically in accordance with the limit provided in GB50077-2003 (8 \%) [29]. Once the thickness exceeds $30 \mathrm{~cm}$, the ratio $f_{\max }$ exceeds the limit of $8 \%$. It is worth mentioning that the thicker the wall is, the larger the difference is between the ratio $f_{\max }$ obtained with the transient and the steady-state methods. When the thickness reaches $120 \mathrm{~cm}$, the ration $f_{\max }$ obtained with the steady-state method reaches $60.17 \%$, showing an increment of $12.68 \%$ compared with that obtained with the transient, which results in the waste of circumferential steel bars in the wall near the bottom of the silo wall. Hence, it is suggested that a transient analytical method or a nonlinear distribution of the temperature gradient is recommended for the design when the wall thickness exceeds $30 \mathrm{~cm}$.

5.2. Parametric Study. Case 2 was defined as the basic model to investigate influenced factors of the temperature effects, which includes meteorological parameters, structural dimensions and the reference temperature. The influences of different factors on silo temperature effect were investigated by comparing the temperature difference, the hoop force $\mathrm{R}_{\mathrm{y}}$ and the circumferential moment $\mathrm{M}_{\mathrm{y}}$ when the silo is full.
5.2.1. Meteorological Parameters. The numerical model of the silo was used to determine the temperature effects of the silos. Figures 14 and 15 present the influences of the meteorological factors on the temperature and internal forces of the silo.

The effects of the daily solar radiation on the positive temperature difference are much higher than that of the negative temperature difference and the temperature difference variations present nonlinear changes (see Figure 14(a)). Further, it can be seen from the Figures 15(a) and 15(d) that the amount of solar radiation increases from $18.3 \mathrm{~W} / \mathrm{m}^{2}$ to $27.9 \mathrm{~W} / \mathrm{m}^{2}$, and the increment reaches by $52.5 \%$. Both the $\mathrm{R}_{\mathrm{y}}$ and the $\mathrm{M}_{\mathrm{y}}$ are no more than $2.2 \%$ of those at $\Delta t_{\text {max,neg }}$. Therefore, the influence of the growth of daily solar radiation on the internal forces at $\Delta t_{\text {max,neg }}$ can be neglected.

In order to analyze the influence of air temperature, the relationship between the daily temperature difference and silo temperature effects was investigated assuming the daily mean temperature as a constant. It can be seen from the Figure 14(b) that variations of maximum temperature difference are approximately proportional to the daily temperature differences. Once the daily temperature difference increases $2.5^{\circ} \mathrm{C}$, the maximum temperature changes by around $1.27^{\circ} \mathrm{C}$. At the occurrence of the maximum negative temperature difference, influences of the daily temperature difference change on $\mathrm{M}_{\mathrm{y}}$ are greater than those of $\mathrm{R}_{\mathrm{y}}$ and the increments of the $\mathrm{M}_{\mathrm{y}}$ are the same for every $2.5^{\circ} \mathrm{C}$ increment in daily temperature difference (see Figures 15(b) and 15(e)).

With the increase of wind speed, the concrete surface and the surrounding air convective heat transfer is accelerated. Therefore, the maximum temperature difference shows a nonlinear decline rend with the increase of wind speed (see Figure 14(c)). The influence of wind speed on the maximum positive temperature difference is more significant than that on the maximum negative temperature difference. It can be seen from Figures 15(c) and 15(f) that the maximum $\mathrm{R}_{\mathrm{y}}$ increases by only $5.31 \%$, and the maximum $\mathrm{M}_{\mathrm{y}}$ increases by $8.12 \%$ at $\Delta t_{\text {max,neg }}$, when the wind speed increases from $2 \mathrm{~m} / \mathrm{s}$ to $12 \mathrm{~m} / \mathrm{s}$.

5.2.2. Dimension of Silo. The simulated results of the influence of these member size factors on temperature and the internal forces of the silo are shown in Figures 16 and 17. Both boundary conditions of inner and outer surfaces and the thickness remain unchanged. As a result, the temperature field barely changes in function of the internal diameter and the ratio of height to diameter (see Figures 16(a) and 16(b)). The effects of wall thickness on both the maximum positive and negative temperature differences are the same. Since the influence depth of solar radiation on temperature of silo wall is about $50 \mathrm{~cm}$, the temperature difference varies nonlinearly with the increasing wall thickness (see Figure 16(c)).

As it can be clearly seen from Figure 17, regarding the whole silo, the internal diameter and the ratio of height to diameter has little effect on the internal forces of the silo wall under solar radiation. The thicker wall is, the larger $R_{y}$ is at the bottom of the silo. Although the wall thickness is different, the positions where the $R_{y}$ reaches zero along the height of silo wall are similar. $\mathrm{M}_{\mathrm{y}}$ increases with the increasing wall 


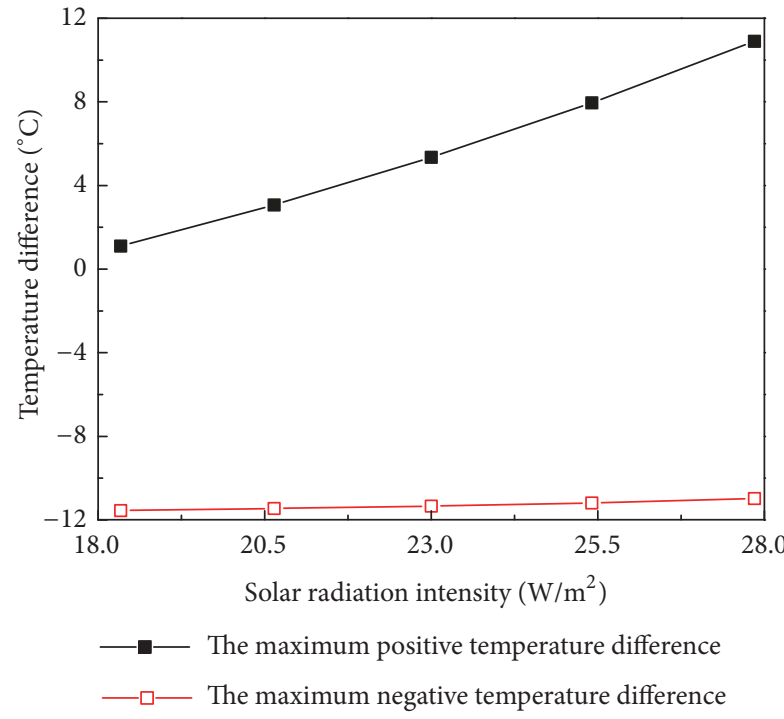

(a)

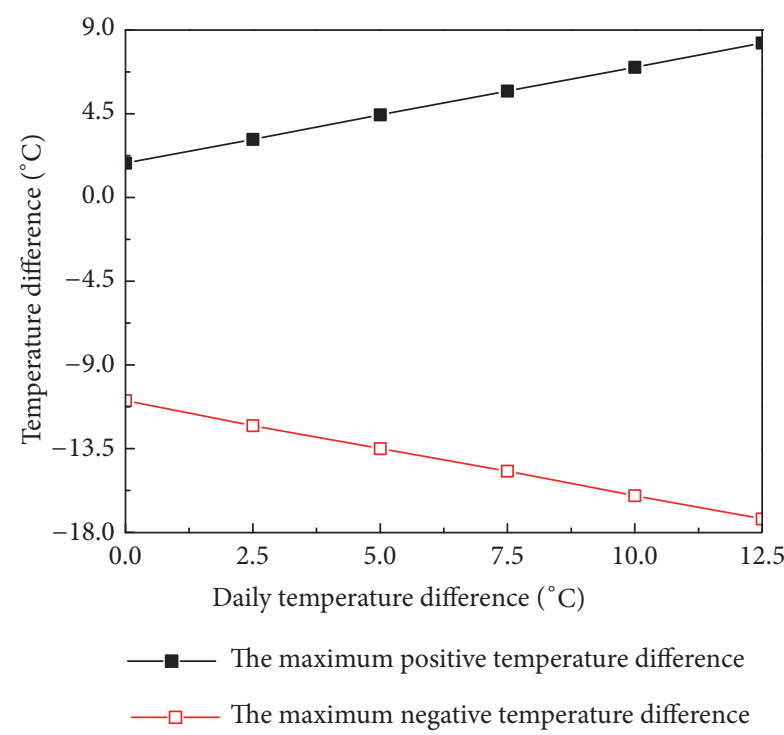

(b)

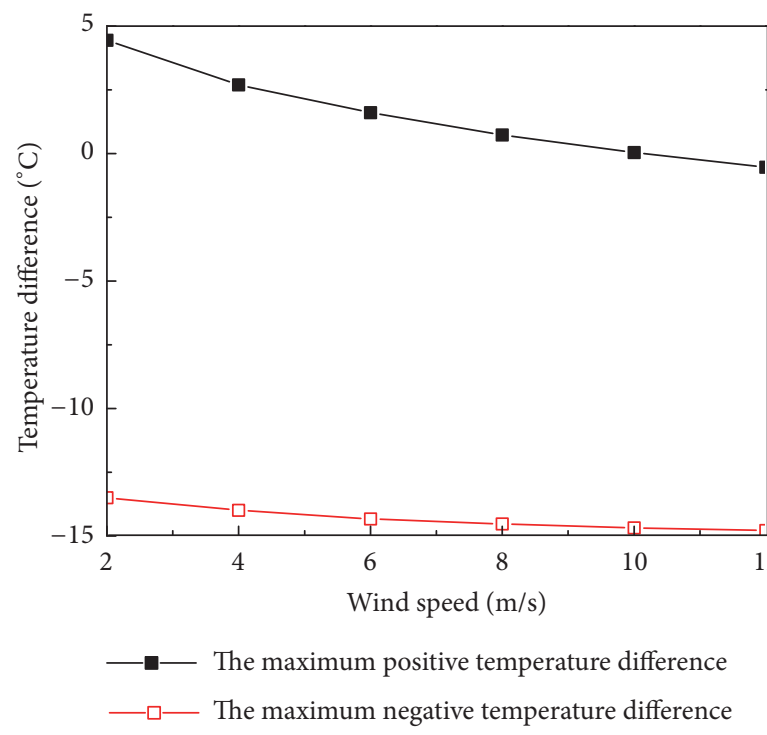

(c)

FiguRE 14: Simulated results of influence of the meteorological factors on temperature. (a) Different solar radiation intensity. (b) Different daily temperature difference. (c) Different wind speed.

thickness. Between the wall thickness of $30 \mathrm{~cm}$ and $60 \mathrm{~cm}$ and for every $10 \mathrm{~cm}$ increment in the wall thickness, the increase of $\mathrm{M}_{\mathrm{y}}$ remains basically stable when the wall thickness is no more than $60 \mathrm{~cm}$ and it increases much more after the wall thickness exceeds $60 \mathrm{~cm}$.

5.2.3. Reference Temperature. Although the reference temperature has no effect on the temperature field distribution of the silo, it directly affects internal forces of the silo. Figure 18 shows the simulated results considering the reference temperature influence on the internal forces of the silo at $\Delta t_{\text {max,neg }}$. Accordingly, the influences of reference temperature on the internal forces are mainly concentrated in the area near the bottom of the silo. The variations amplitudes of the internal forces at the bottom of the silo are linearly proportional to the increase of the reference temperature. At a height of 10 $\mathrm{m}$ from the bottom of the silo, the internal forces of the silo wall are not affected by the reference temperature any more. Taking an examination of the temperature increment of every $10^{\circ} \mathrm{C}, \mathrm{R}_{\mathrm{y}}$ at the bottom increases about $3144.70 \mathrm{kN} / \mathrm{m}$ and $\mathrm{M}_{\mathrm{y}}$ increases about $107.97 \mathrm{kN} \cdot \mathrm{m} / \mathrm{m}$. Therefore, it is recommended that the average temperature during the construction of silo should not exceed $20^{\circ} \mathrm{C}$.

\section{Conclusions}

(1) From the analysis of on-site measurements, it can be found that the temperature of the outer surface of the wall 


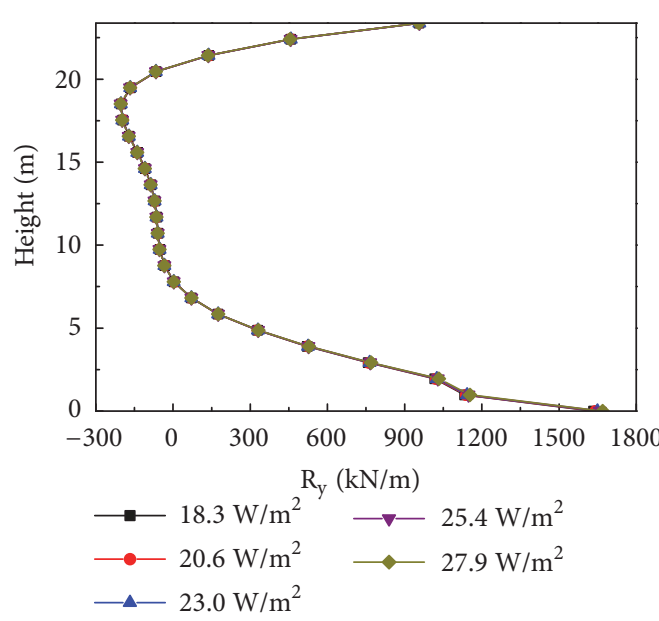

(a)



(c)

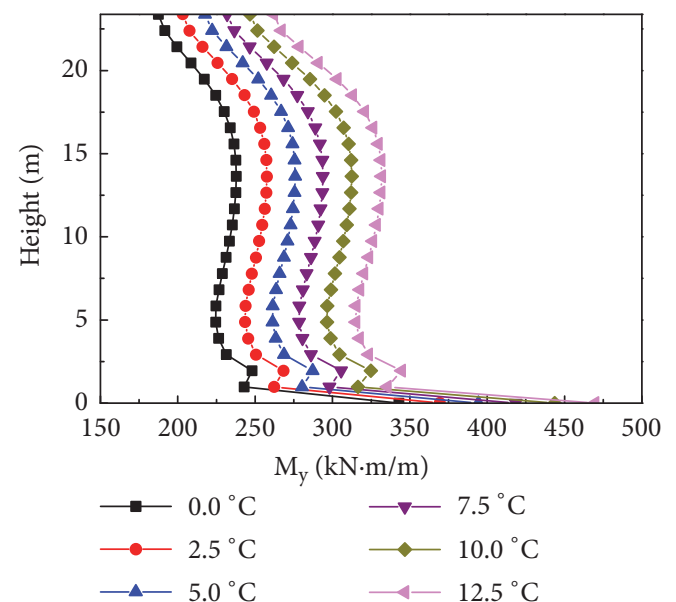

(e)

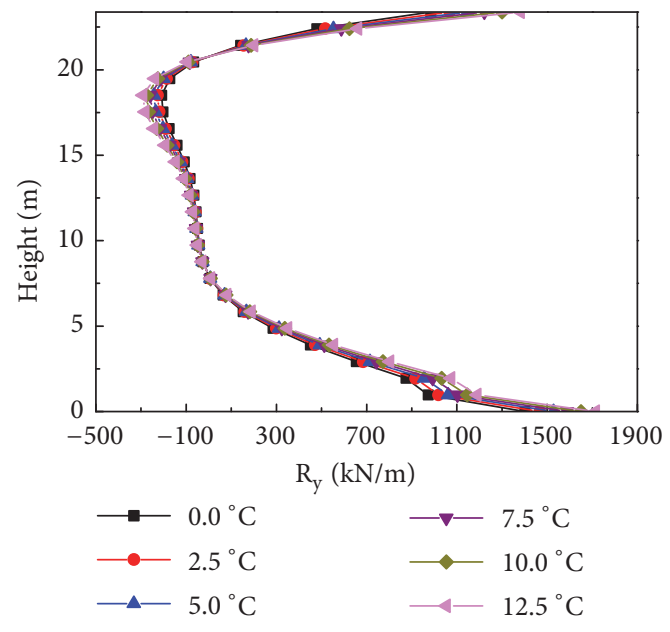

(b)

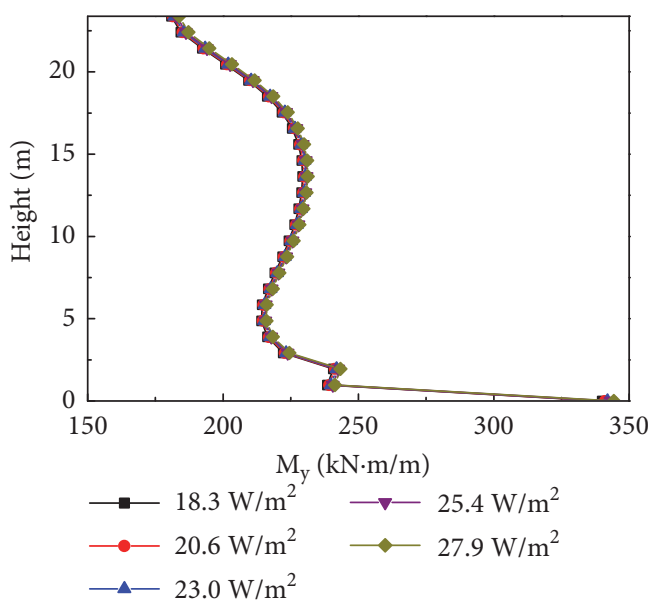

(d)



(f)

FIGURE 15: Internal forces under different meteorological factors at $\Delta t_{\text {max neg. }}$ (a) $\mathrm{R}_{\mathrm{y}}$ under different solar radiation intensity. (b) $\mathrm{R}_{\mathrm{y}}$ under different daily temperature difference. (c) $R_{y}$ under different wind speed. (d) $M_{y}$ under different solar radiation intensity. (e) $M_{y}$ under different daily temperature difference. (f) $\mathrm{M}_{\mathrm{y}}$ under different wind speed. 


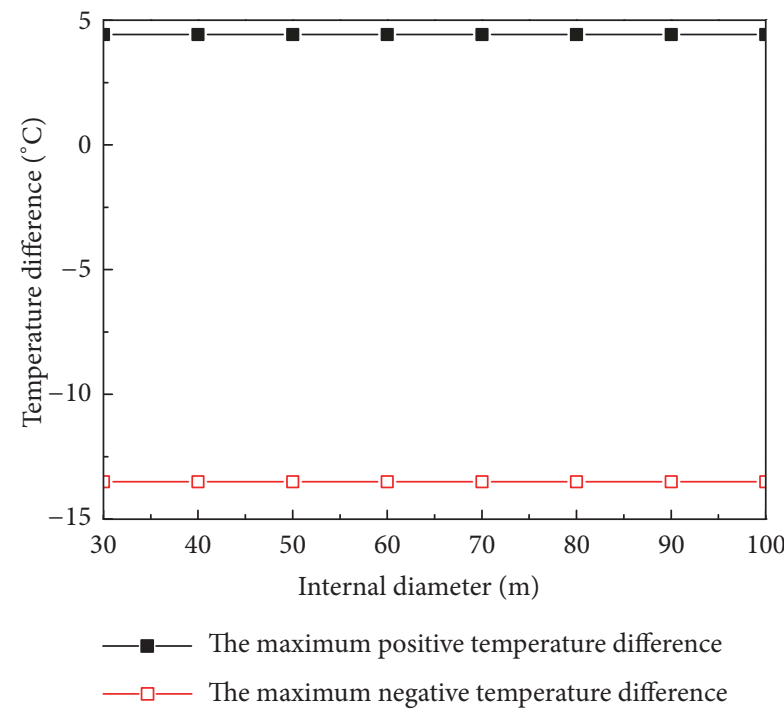

(a)

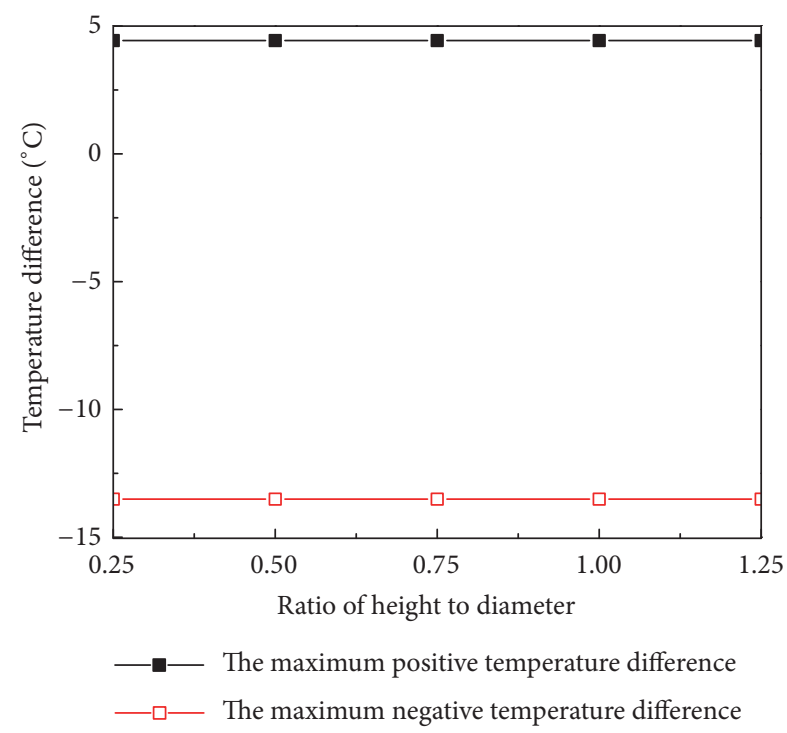

(b)



(c)

Figure 16: Simulated results of influence of member size factors on temperature. (a) Different internal diameter. (b) Different ratio of height to diameter. (c) Different wall thickness.

is mainly affected by solar radiation and air temperature. The temperature of inner surface of the empty silo affected by the inside air temperature changes insignificantly. Further, the temperature of inner surface of the test section tends to be stable when the thermal stored material load reaches the full state, and it changes within $1^{\circ} \mathrm{C}$ in one day.

(2) The finite element simulation shows that the temperature gradient exhibits a significant nonlinearity along the wall thickness. With respect to temperature effects, the time of maximum negative temperature difference in case of the full silo is the most unfavorable. Further, the temperature gradient obtained with the steady-state method is linearly distributed along the wall thickness, while that obtained with the transient method is nonlinear. Therefore, internal forces obtained with the transient method are smaller than those obtained with the traditional steady-state method.

(3) Regarding the thickness of more than 30 centimeters, results calculated as a nonlinear distribution along the thickness of the wall are more optimized than those considered as a linear distribution. Therefore, it is suggested that a nonlinear distribution of temperature difference along the thickness of the wall is more practical when analyzing the temperature effects of large-diameter concrete silos.

(4) The parameter analysis shows that (1) the solar radiation and wind speed have significant influences on the positive temperature difference but a minor influence on the negative temperature difference at night; (2) there is 


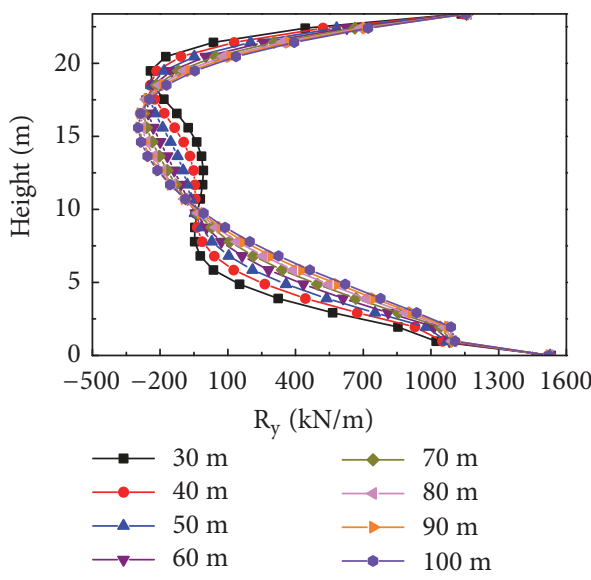

(a)

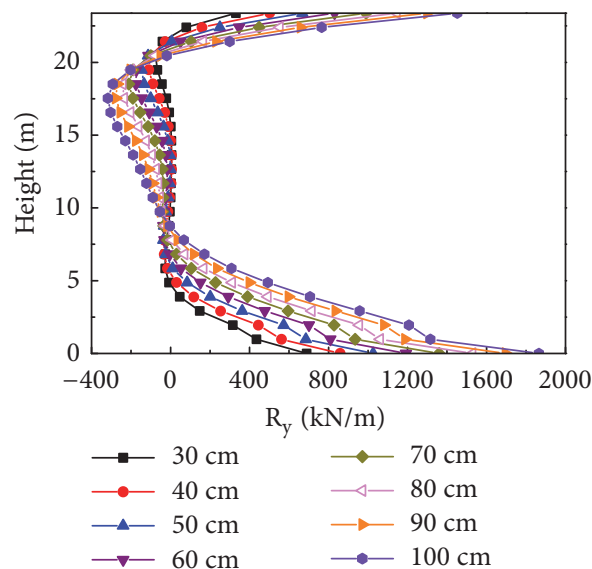

(c)

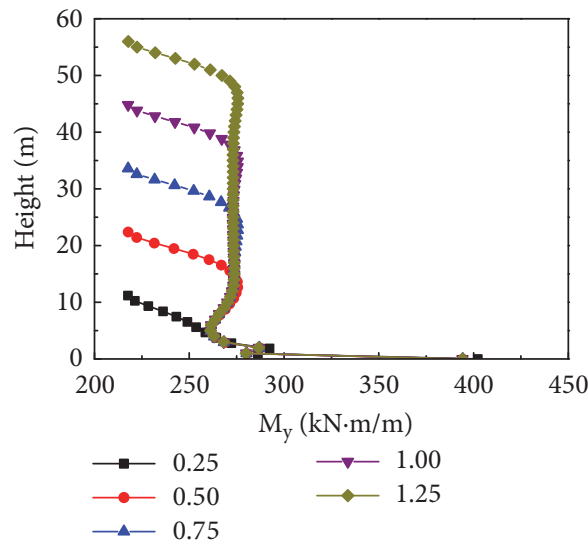

(e)

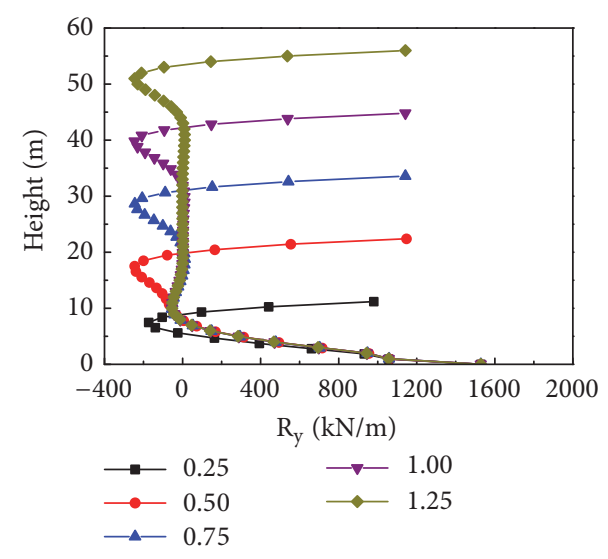

(b)

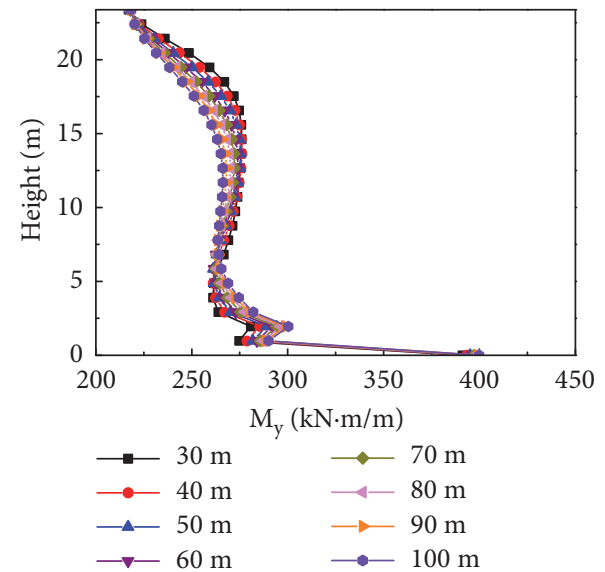

(d)

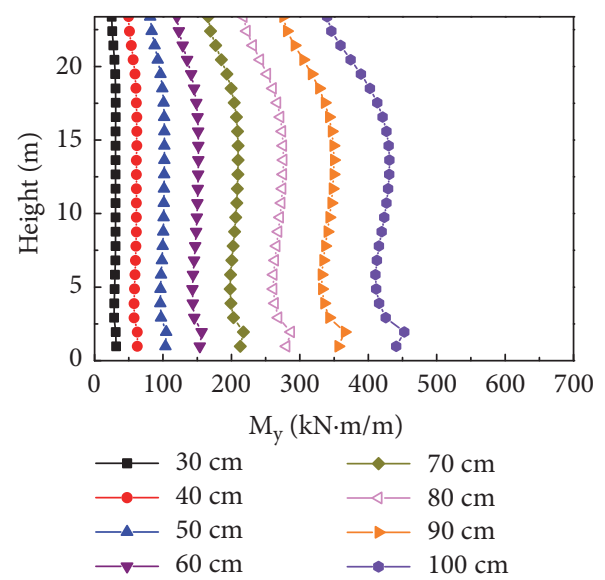

(f)

Figure 17: Internal forces under different member size at $\Delta t_{\text {max, neg. }}$ (a) $\mathrm{R}_{\mathrm{y}}$ under different internal diameter. (b) $\mathrm{R}_{\mathrm{y}}$ under different ratio of height to diameter. (c) $R_{y}$ under different wall thickness. (d) $M_{y}$ under different internal diameter. (e) $M_{y}$ under different ratio of height to diameter. (f) $M_{y}$ under different wall thickness.

an approximate linear relationship between the maximum temperature difference and the daily temperature difference; (3) the wall thickness has a significant influence, while the internal diameter and height-diameter ratio have an insignificant influence on the temperature effect. The maximum negative temperature difference and internal forces of the silo increase with the increasing wall thickness; (4) the higher the reference temperature is, the larger the internal 


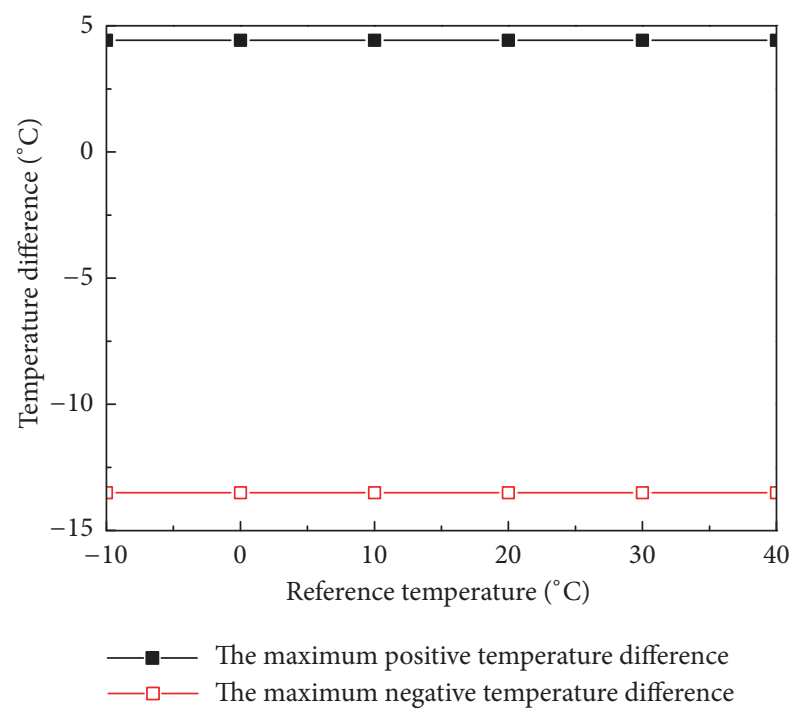

(a)

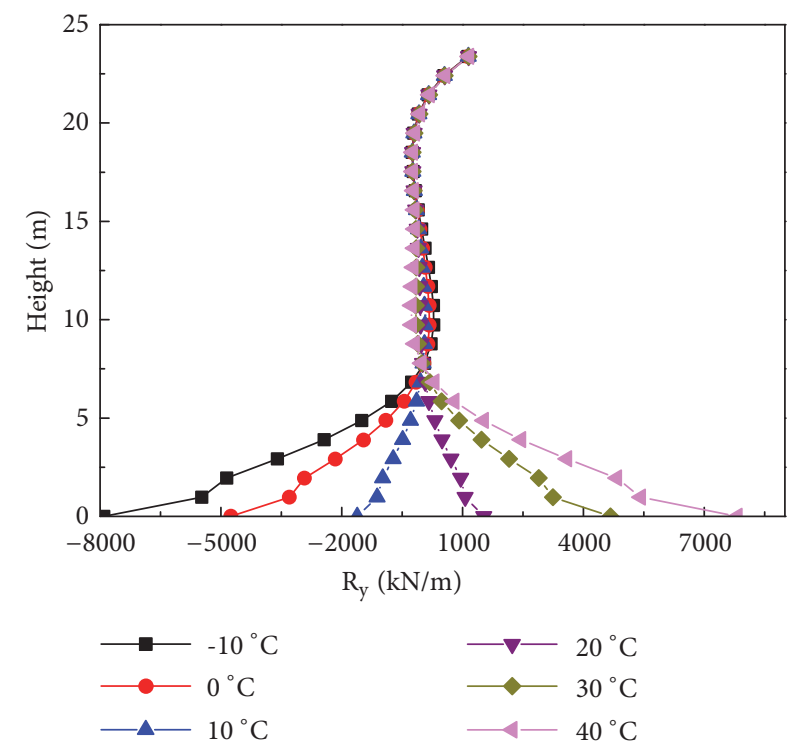

(b)

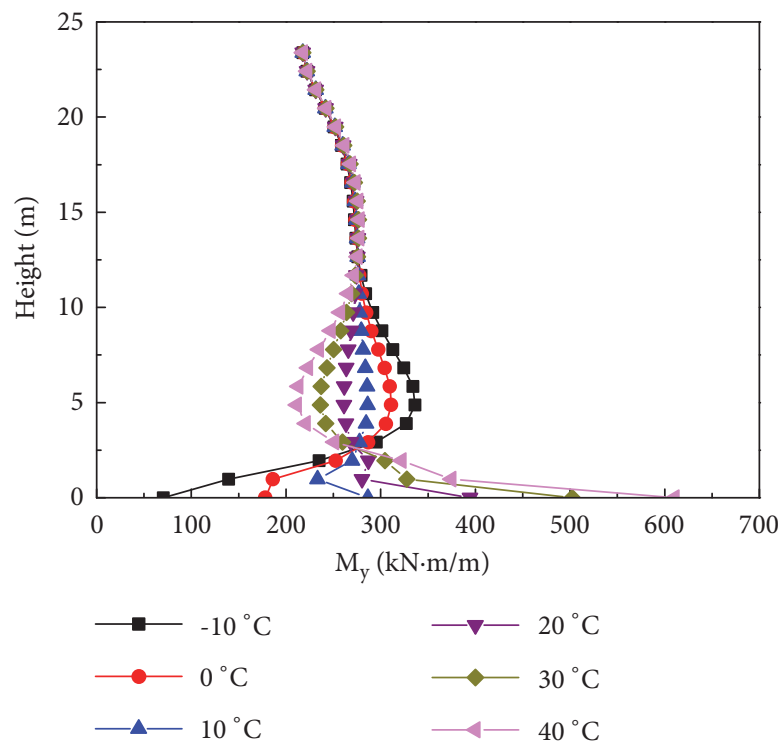

(c)

FIGURE 18: Simulated results of influence of the reference temperature on temperature and internal forces. (a) Temperature. (b) The hoop force $\mathrm{R}_{\mathrm{y}}$. (c) The circumferential moment $\mathrm{M}_{\mathrm{y}}$.

forces are. Hence, it is suggested that the average construction temperature of the silo should not exceed $20^{\circ} \mathrm{C}$.

\section{Data Availability}

The data used to support the findings of this study are available from the corresponding author upon request.

\section{Conflicts of Interest}

The authors declare that they have no conflicts of interest.

\section{References}

[1] Y. Wang, Y. Zhan, and R. Zhao, "Analysis of thermal behavior on concrete box-girder arch bridges under convection and solar radiation," Advances in Structural Engineering, vol. 19, no. 7, pp. 1043-1059, 2016.

[2] Y.-h. Wang, Y.-s. Zou, C.-j. Li, L.-q. Xu, and S.-c. Wang, "Analytical methods for temperature field and temperature stress of column pier under solar radiation," Mathematical Problems in Engineering, vol. 2015, Article ID 278072, 8 pages, 2015. 
[3] A. Dogangun, Z. Karaca, A. Durmus, and H. Sezen, "Cause of damage and failures in silo structures," Journal of Performance of Constructed Facilities, vol. 23, no. 2, pp. 65-71, 2009.

[4] M. Maj, "Some causes of reinforced concrete silos failure," Procedia Engineering, vol. 172, pp. 685-691, 2017.

[5] Z. Song, J. Xiao, and L. Shen, "On temperature gradients in high-performance concrete box girder under solar radiation," Advances in Structural Engineering, vol. 15, no. 3, pp. 399-415, 2012.

[6] G.-D. Zhou and T.-H. Yi, "A summary review of correlations between temperatures and vibration properties of long-span bridges," Mathematical Problems in Engineering, vol. 2014, Article ID 638209, 19 pages, 2014.

[7] R. Westgate, K. Koo, and J. Brownjohn, "Effect of solar radiation on suspension bridge performance," Journal of Bridge Engineering, vol. 20, no. 5, Article ID 04014077, 12 pages, 2015.

[8] X. Song, H. Melhem, J. Li, Q. Xu, and L. Cheng, "Effects of solar temperature gradient on long-span concrete box girder during cantilever construction," Journal of Bridge Engineering, vol. 21, no. 3, 2016.

[9] J. M. Morán, A. Juan, R. Robles, and P. J. Aguado, "Effects of Environmental Temperature Changes on Steel Silos," Biosystems Engineering, vol. 94, no. 2, pp. 229-238, 2006.

[10] H. Liu, Z. Zhang, Z. Chen, and Q. Chen, "Research on temperature field and temperature effect of steel silos under solar radiation," Journal of Building Structures, vol. 37, no. 8, pp. 151-157, 2016.

[11] J. Y. Ooi and K. M. She, "Finite element analysis of wall pressure in imperfect silos," International Journal of Solids and Structures, vol. 34, no. 16, pp. 2061-2072, 1997.

[12] F. Ayuga, M. Guaita, P. J. Aguado, and A. Couto, "Discharge and the eccentricity of the hopper influence on the silo wall pressures," Journal of Engineering Mechanics, vol. 127, no. 10, pp. 1067-1074, 2001.

[13] P. Vidal, M. Guaita, and F. Ayuga, "Analysis of dynamic discharge pressures in cylindrical slender silos with a flat bottom or with a hopper: Comparison with eurocode 1," Biosystems Engineering, vol. 91, no. 3, pp. 335-348, 2005.

[14] P. Vidal, A. Couto, F. Ayuga, and M. Guaita, "Influence of hopper eccentricity on discharge of cylindrical mass flow silos with rigid walls," Journal of Engineering Mechanics, vol. 132, no. 9, pp. 1026-1033, 2006.

[15] J. B. Fu, M. T. Luan, Q. Yang, and T. K. Nian, "Threedimensional finite element analysis of wall pressure on large diameter silos," Journal of Convergence Information Technology, vol. 5, no. 7, pp. 120-128, 2010.

[16] M. Carrera-Rodríguez, G. M. Martínez-González, J. L. Navarrete-Bolaños, J. E. Botello-Álvarez, R. Rico-Martínez, and H. Jiménez-Islas, "Transient numerical study of the effect of ambient temperature on 2-D cereal grain storage in cylindrical silos," Journal of Stored Products Research, vol. 47, no. 2, pp. 106-122, 2011.

[17] G. Y. Ren, Y. A. Liu, W. Peng, X. Duan, and L. D. Zhang, "Experimental and numerical research on squat silo and large size horizontal warehouse during quasi-steady-state storage," International Journal of Agricultural and Biological Engineering, vol. 9, no. 6, pp. 214-222, 2016.

[18] F. Tan, B. Kayisoglu, and E. Okur, "Effects of compaction pressure on the temperature distribution in bunker type silage silo," Indian Journal of Animal Sciences, vol. 88, no. 1, pp. 116-120, 2018.
[19] S. Jiang and J. C. Jofriet, "Finite element prediction of silage temperatures in tower silos," Transactions of the ASAE, vol. 30, no. 6, pp. 1744-1750, 1987.

[20] D. R. Kong and W. M. Pu, "Study on temperature action of coal silo with a diameter of 40 meters," Special Structures, vol. 15, no. 2, pp. 32-38, 1998.

[21] A. Lapko, M. Gnatowski, and J. A. Prusiel, "Analysis of some effects caused by interaction between bulk solid and r.c. silo wall structure," Powder Technology, vol. 133, no. 1-3, pp. 44-53, 2003.

[22] A. Łapko and J. A. Prusiel, "Analysis of thermal effects in grouped silos of grain elevators," International Agrophysics, vol. 20, no. 4, pp. 301-307, 2006.

[23] T. H. Chen, Q. Peng, and Z. J. Tang, "Field measurement and analysis of coal temperature and lateral pressure for large diameter circular coal silo," Engineering Journal of Wuhan University, vol. 45, no. 3, pp. 366-369, 2012.

[24] D. Lippold, "Post-tensioned silo walls with high post-tensioning degree and transient temperature effects," Beton- und Stahlbetonbau, vol. 107, no. 10, pp. 679-689, 2012.

[25] Z. Chen, X. Li, Y. Yang, S. Zhao, and Z. Fu, "Experimental and numerical investigation of the effect of temperature patterns on behavior of large scale silo," Engineering Failure Analysis, vol. 91, pp. 543-553, 2018.

[26] D. Chen, H. Qian, H. Wang, Y. Chen, F. Fan, and S. Shen, "Experimental and numerical investigation on the non-uniform temperature distribution of thin-walled steel members under solar radiation," Thin-Walled Structures, vol. 122, pp. 242-251, 2018.

[27] F. Kehlbeck, Effect of Solar Radiation on Bridge Structures, China Railway Publishing House, Beijing, China, 1981, Translated by: F. X. Lu.

[28] B. X. Chen and Y. P. Yao, "Statistical distribution regularity of insolation temperature on reinforced concrete chimneys," Journal of Civil Engineering, vol. 25, no. 6, pp. 58-65, 1992.

[29] GB, "Code for design of reinforced concrete silos," Tech. Rep. GB 50077-2003, China National Coal Construction Association, Beijing, China, 2003.

[30] Z. Y. Hu, Q. Sun, L. Zhang, and W. Zhao, "Study on the wall stress of silo filled with cement clinker under the coaction of temperature load and horizontal pressure," Industrial Construction, vol. 21, pp. 205-208, 2005. 


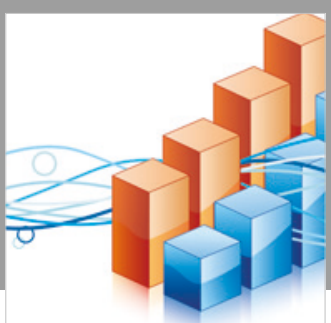

Advances in

Operations Research

\section{-n-m}
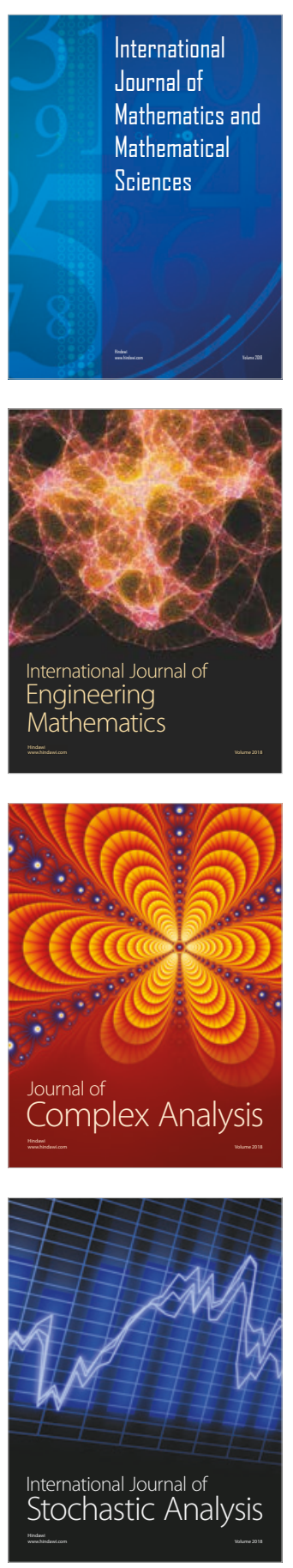
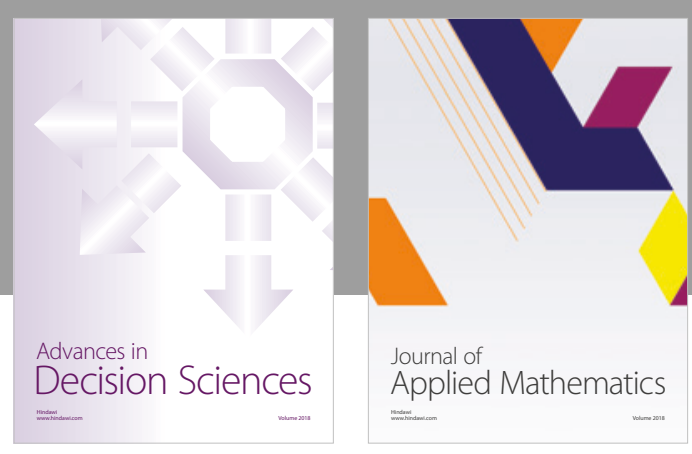

Journal of

Applied Mathematics
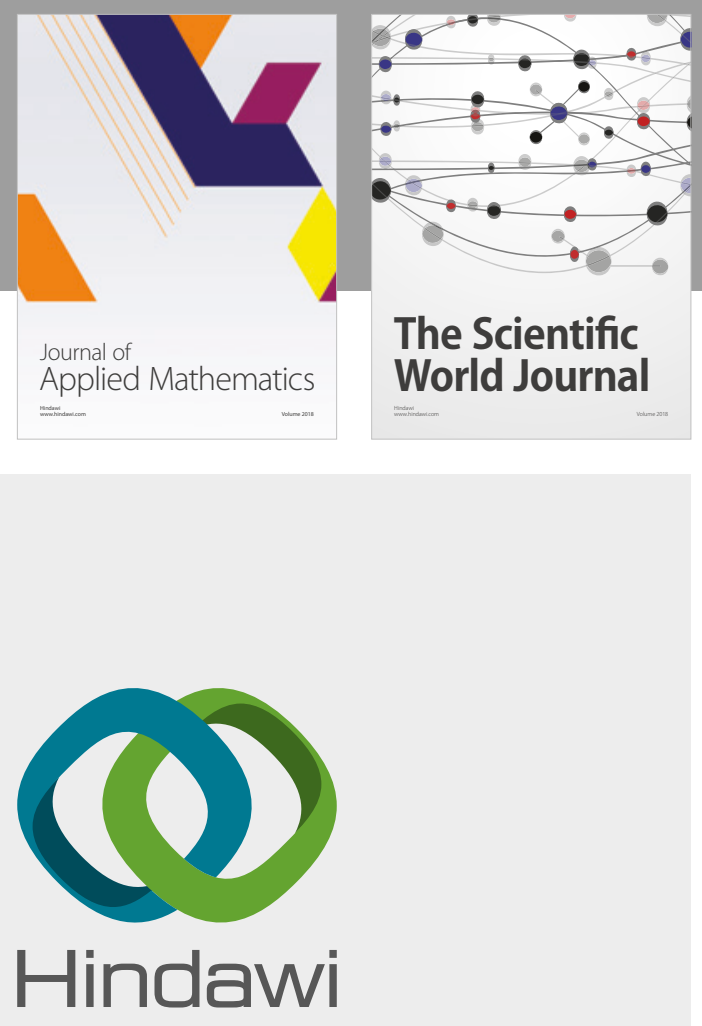

Submit your manuscripts at

www.hindawi.com

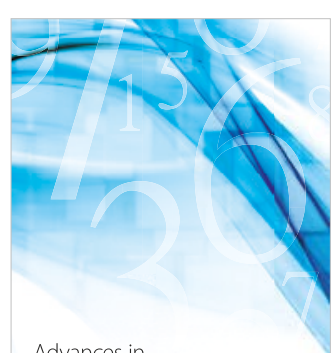

Advances in
Numerical Analysis
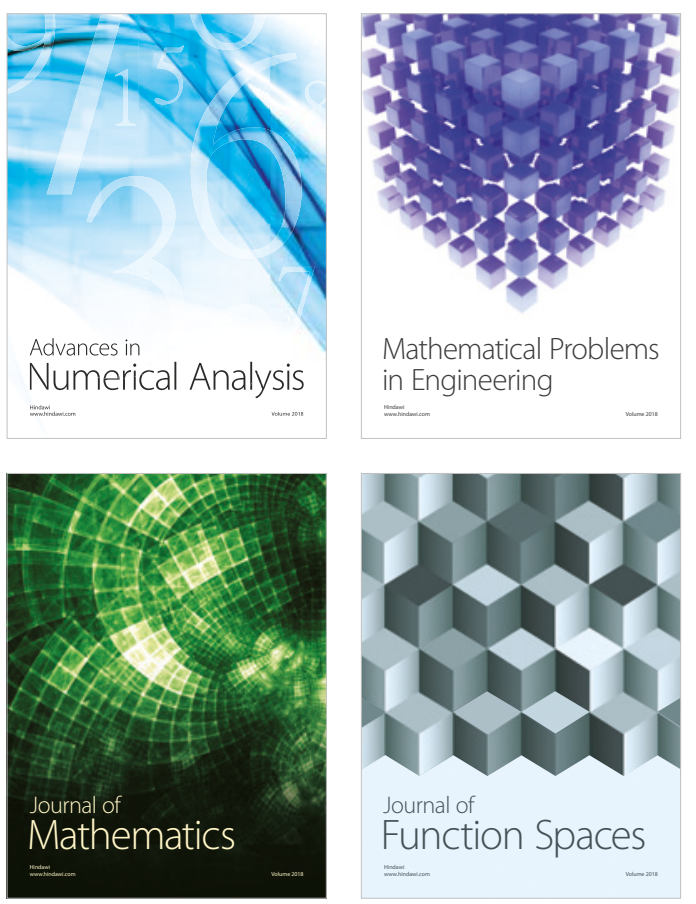

Mathematical Problems in Engineering

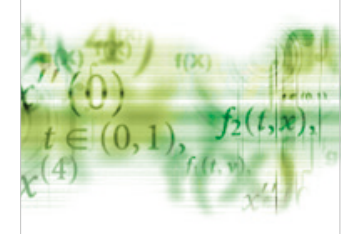

International Journal of

Differential Equations

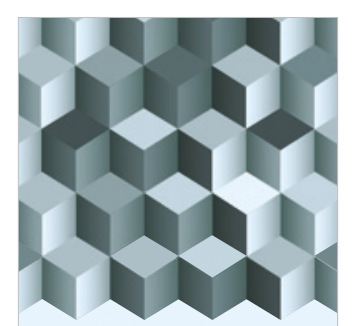

Journal of

Function Spaces
The Scientific

World Journal

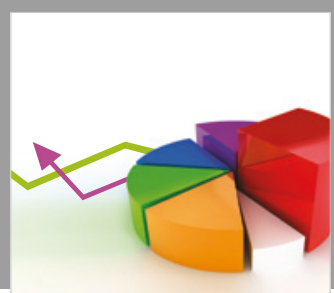

Journal of

Probability and Statistics
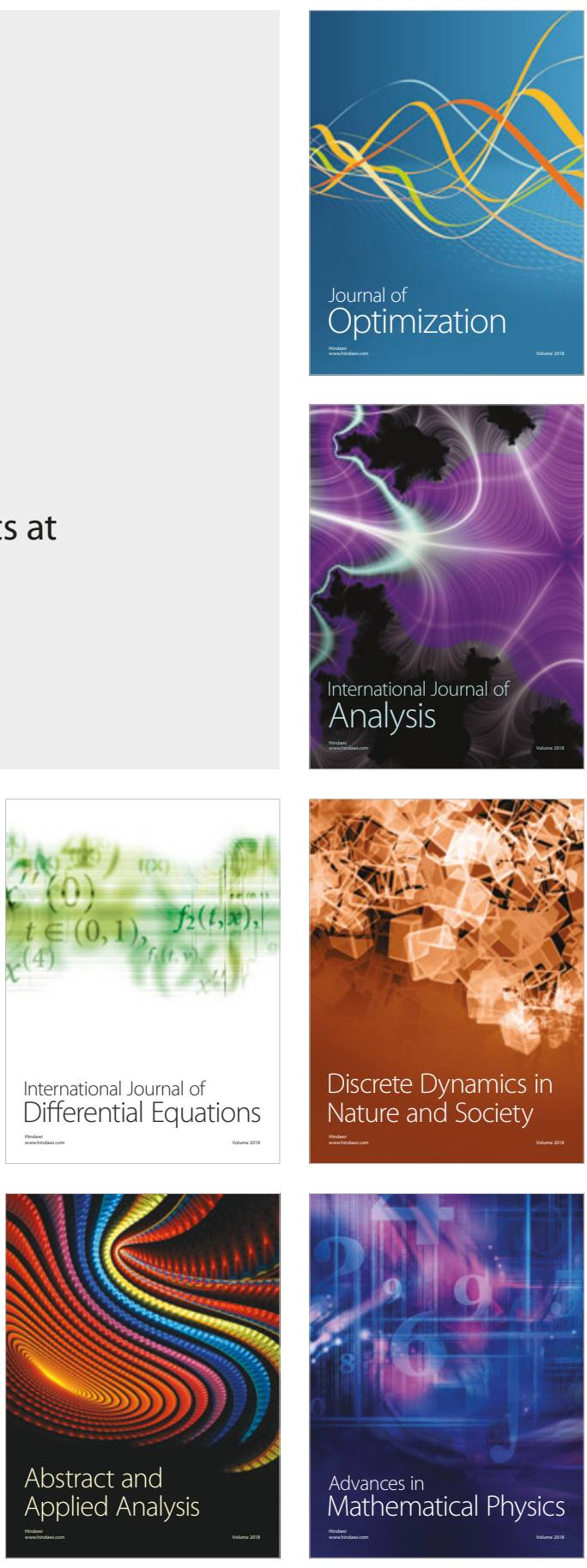